\title{
Research and applications of nuclear tracks: Developments in Pakistan and global comparison
}

\author{
Mukhtar Ahmed Rana
}

Instrument Development and Maintenance (IDM), Physics Division, Pakistan Institute of Nuclear Science and Technology (PINSTECH), Islamabad, Pakistan; ranamssa@gmail.com, marana@pinstech.org.pk

Received 31 August 2012; revised 30 September 2012; accepted 14 October 2012

\begin{abstract}
The present paper describes the development and applications of nuclear track detection technique in Pakistan. Pakistan entered in the field of nuclear tracks in early 1970s when it was still quite new. Highlights of successes of different Pakistani laboratories, working on nuclear tracks, achieved on their own or in collaboration with similar centers in the world are described briefly. The robust features of this investigation are the comprehensive investigation of the addressed research, analysis and review of results, and discussions with the perspectives of applications and new research directions. Further analysis of the published results by the present author and some new results are also presented. This paper portrays a comprehensive picture of the nuclear track detection research and technology in Pakistan and can be useful for a similar development in any country around the globe.
\end{abstract}

Keywords: Nuclear Tracks; Latent Tracks; Annealing; Chemical Etching; Radionuclides; Nanotechnology Formatting

\section{INTRODUCTION}

Particle detectors are essentially required for experimental investigations of radioactivity, nuclear interacttions, particle physics and cosmic rays. A solid state nuclear track detector (SSNTD) [1-4] is a sample of a plastic, glass or crystal capable of preserving the damage of a penetrating radiation, especially a charged particle. This damage or latent tracks show preferential etching compared to the undamaged material [5-9]. Diameter, length and shape of the etched track carry information about energy, charge, mass and incident angle of the detected particle. Due to advantages of simplicity, low cost and sturdy construction of such detectors, this technique is quite common in developing countries and being used in various areas of research and industry like radiation dosimetery, studies of nuclear reactions and exploration of uranium etc. In a way, the knowledge about nuclear track formation is useful in nuclear waste immobilization $[10$, 11] and ion implantation in semiconductors [12].

First SSNTDs based group was established by Dr. H. A. Khan at Nuclear Engineering Division of PINSTECH, Islamabad in 1974. Name of the group was SSNTDs Laboratory, PINSTECH. This group established facilities nuclear research, development and applications and applied this technique in various fields of science and technology. Details will be given in the next section. After that, this research field extended to different universities and research centers of Pakistan through collaboration with SSNTDs Laboratory, PINSTECH or independent efforts. This paper describes the development of this research activity in Pakistan and highlights of selected results.

\section{NUCLEAR TRACK RESEARCH IN PAKISTAN}

\subsection{General Statistics}

Pakistan entered in the development of nuclear track detection technique and its applications shortly after invention of this technique. Initially, this research remains at the stage of student research projects for some time. The research in this field started publishing in international journals in 1975 after which it continued in a good manner as clear from Figure 1. In last more than 3 decades, SSNTDs were employed in numerous and diversified fields of science and technology in Pakistan. Papers published in various fields are classified in Table 1 which shows the real breadth of applications of SSNTDs in Pakistan. Fields of applications include physics, chemistry, engineering medicine, health sciences and many others. Pakistan is a developing country. This simple and low cost technique proved to be quite fit for this environment. So, SSNTDs in Pakistan is a success story. 


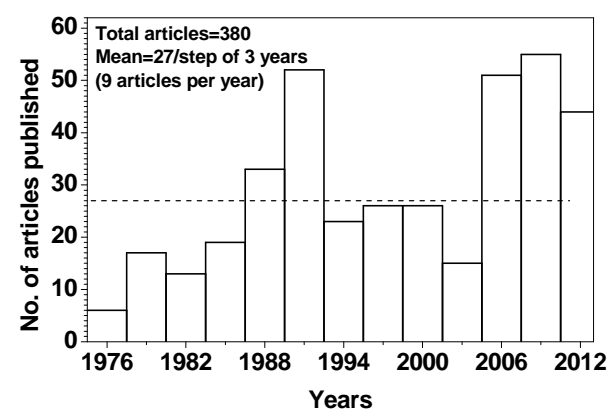

Figure 1. Number of articles published per step of 3 years starting from 1975. Dashed line shows the average. Analysis is performed from the raw data obtained from Scopus (www.scopus.com).

Table 1. Summary of articles published starting from 1975 to todate in international journals in fields of development and of SSNTDs. Number of articles in specific fields or categories.

\begin{tabular}{cccc}
\hline Years & $\begin{array}{c}\text { No. of } \\
\text { articles }\end{array}$ & Field/Category & $\begin{array}{c}\text { No. of } \\
\text { articles }\end{array}$ \\
\hline $1975-1977$ & 6 & Physics \& Astronomy & 167 \\
$1978-1980$ & 17 & Engineering & 58 \\
$1981-1983$ & 13 & Medicine & 31 \\
$1984-1986$ & 19 & Energy & 30 \\
$1987-1989$ & 33 & Health Sciences & 29 \\
$1990-1992$ & 52 & Materials Science & 23 \\
$1993-1995$ & 23 & Chemistry & 5 \\
$1996-1998$ & 26 & Earth \& Planetary Sciences & 3 \\
$1999-2001$ & 26 & Toxicology & 3 \\
$2002-2004$ & 15 & Multidisciplinary \& & 90 \\
$2005-2007$ & 51 & Undefined & \\
\hline
\end{tabular}

\subsection{SSNTDs Laboratories}

There are a number of laboratories in Pakistan equipped with functional facilities of chemical etching of nuclear track detectors and microscopy of nuclear tracks. Laboratories which have actively published their research in international journals include Pakistan Institute of Nuclear Science and Technology (PINSTECH) Laboratory, Islamabad, Pakistan Institute of Engineering and Applied Sciences (PIEAS) Laboratory, Islamabad, Gomal University Laboratory, D. I. Khan, CIIT Laboratory, Islamabad, Quaid-i-Azam University Laboratory, Islamabad, UET laboratory, Lahore and GCU Laboratory, Lahore. There are other universities which only use SSNTDs laboratories for the purpose of teaching and student research projects at Bachelor's and Master's degrees.

\subsection{Research Areas and Highlights}

\subsubsection{Nuclear Track Methodology}

\subsubsection{Nuclear Track Formation}

A latent charged particle track may be divided in to two zones, central core zone and outer shell (OS), shown in Figure 2. Fast electrons carry energy out of the core zone immediately after passage of the incident particle. Incident particle and secondary electrons ( $\delta$-rays) produce Auger electrons which play an important role in producing the damage in the latent track. Due to their low energy, Auger electrons form localized spikes which serve as nucleation centres for extended defects in the latent tracks. These extended are supposed to show excessive preferential chemical etching due to severely broken molecular structure of the target material. Number density of Auger decays is $\eta_{\text {auger }}^{\text {total }}=\eta_{\text {auger }}^{\text {ion }}+\eta_{\text {auger }}^{\delta}$.

Deposited Auger energy density in the central core (Figure 2) is only due to Auger electrons produced by interaction of incident charged particle primary collisions with target atoms which is given by $\varepsilon_{\text {core }}^{\text {Auger }} \approx \varepsilon_{\text {core }}^{\text {ion }}$ whereas deposited Auger energy density in outer shell ( $\varepsilon_{O S}^{\text {Auger }}$ ) can be expressed as $\varepsilon_{O S}^{\text {Auger }} \approx \varepsilon_{\text {core }}^{\delta}+\varepsilon_{O S}^{\delta}$. The terms $\varepsilon_{\text {core }}^{\delta}$ and $\varepsilon_{O S}^{\delta}$ are deposited Auger energy densities due to Auger electrons generated by $\delta$-rays produced, respectively, in central core and outer shell. A target material serves as a track detector if instantaneous track defect annihilation $\left(r_{a}^{d}\right)$ and build up $\left(r_{b}^{d}\right)$ reactions obey the following relationship $r_{a}^{d}=\alpha r_{b}^{d}$. The parameter $\alpha$ is a dimensionless quantity with value, $0<\alpha<1$. Lower value of $\alpha$ for a track detector will mean higher detection sensitivity. The word "defect" here can be understood as the presence of an atom at non-equilibrium position in a perfect structure with atoms at equilibrium positions whereas extended defect is a bigger structure composed of multiple such point defects. Radial and axial rates of track etching yield some of the important information about track forming particles. The appropriate identification or almost complete characterization of track forming particles is only possible if a valid calibra-

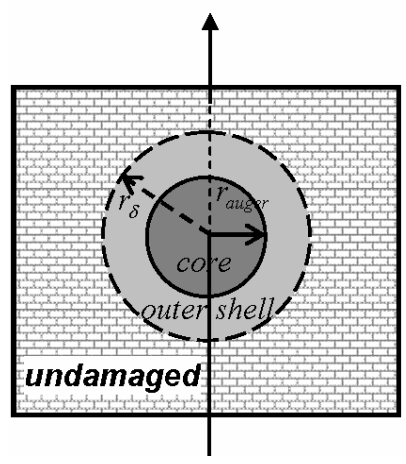

Figure 2. Structure of single radiation damage in a solid. 
tion is available. Generally, the calibration for charged particle identification in track detection method is between restricted energy loss (REL) of particle in the detector and the reduced etch rate or track to bulk etch rate ratio.

It is discussed why track detectors (e.g., CR-39 and CN-85), composed of oxygen or lighter elements, are highly sensitive and efficient compared with those (e.g., glass and mica), partly or fully composed of elements heavier than oxygen. Weak scattering (or angular deflecttion) of incident particles by light target atoms (oxygen and lighter) in track detectors (e.g., CR-39 and CN-85) do not deviate incident particles from their straight paths while these target atoms recoil considerably in the target damaging structure of the detector. Heavy atoms in some other track detectors (like $\mathrm{Si}$ in glass) scatter or deflect incident particles through a wide angle deviating them from their straight paths while target atoms themselves recoil weakly in the target producing less damage than the case of CR-39. TRIM and channelling simulations of passage of $2 \mathrm{MeV}$ protons through selected targets are presented to demonstrate these conceptions about nuclear track formation. Skewness represents the left-right symmetry of a statistical distribution and can have 0 , negative or positive value. Values of skewness, kurtosis and skewness/range are given in Table 2. The negative skew in the longitudinal range means that the distribution is asymmetric to the left, i.e. the tail extends towards range values that are shorter than the most probable value.

The shorter penetration depths are associated with protons that have suffered wide angle scattering in the target. The magnitude of the skewness gives a measure of wide angle scattering of protons in the target. The skewness per unit range in Sodalime Glass is $67 \%$ higher than that in CR-39. The kurtosis values indicate the extent of deviation of proton range distribution from Gaussian distribution (with a value 3.0 for the standard Gaussian distribution). Longitudinal, lateral and radial ranges with corresponding straggles of $2 \mathrm{MeV}$ protons in CR-39 and Sodalime Glass targets are given in Table 2. The angle of the three dimensional cone containing twenty thousand $2 \mathrm{MeV}$ protons implanted into two targets (CR-39 and Sodalime Glass) is given by $\theta=\tan ^{-1} \frac{R_{r}}{R_{l}}$. Values of cone angle $\theta$ for CR-39 and Sodalime Glass targets are in Table 1. Higher value of cone angle for Sodalime Glass $\left(2.56^{\circ}\right)$ compared with that of CR-39 $\left(1.66^{\circ}\right)$ supports the observation that trajectories are more skewed in it.

\subsubsection{Chemical Etching of Latent Particle Tracks}

Chemical etching is the essential procedure in nuclear track detection and its applications in nanofabrication. Chemical etching of nuclear tracks involves chemical processes and need to be studied both experimentally and theoretically [13]. A considerable amount of work was done on etching optimization of CR-39 by the PIEAS group lead by Matiullah [14,15]. The same procedure was also investigated by PINSTECH group. Their main focus was on properties and effects of etch products in etchants [16-18]. A latent track can be divided into three volumetric regions along the radial direction. Central cylindrical core has high porosity due to evaporation of free or loosely bound atoms in the broken molecular structure and coulomb explosion. Shell 1 surrounds the central core and contains compressed material due to coulomb displacement or thermal movement of atoms into it from central core producing high energy bonds between atoms. Shell 2 has the same atomic density as bulk material and contains a significantly lower defect density compared with central core and shell 1 . The surface-cap segment of the central core of the track becomes chemically different from its lower part and bulk material due to atomic transport between this segment and environment. Presence of high temperature and possibility of atomic transport between surface-cap segment and environment enhances the probability of formation of chemical phases with lower free energy compared with that of lower segment. The same thing will happen in surface-cap segment of shell 2 with lower intensity. Lower free energy material in surface-cap segment will have higher activation energy of etching compared with the centre and bottom of the latent track leading to reduced track etch rate near the surface causing the etch induction time. Another reason for reduction of track etch rate near the surface is absence of pit at the start of etching. Figure 3 is a plot between EIT and $Z / \beta$. The $Z / \beta$ value for the heavy fragment $\mathrm{Ba}$ was used in Figure 3 . This plot is a calibration curve, which can be used to classify particles on the basis of $\mathrm{Z} / \beta$ in CR-39 detector.

Table 2. Comparison between mean values of axial, lateral and radial ranges and corresponding straggles for CR-39 and Sodalime Glass. Values of skewness, kurtosis, skewness/range and cone angle for these detectors are also given.

\begin{tabular}{cccccccc}
\hline \multirow{2}{*}{ Detectors } & \multicolumn{3}{c}{ Range (Straggle) $\boldsymbol{\mu m}$} & Skewness & Kurtosis & $\begin{array}{c}\text { Skewness/Range } \\
\boldsymbol{\mu n m}\end{array}$ \\
\cline { 2 - 4 } & Axial & Lateral & Radial & & & & Cone Angle $\boldsymbol{\theta}$ \\
\hline CR-39 & $59.4(1.1)$ & $1.09(1.6)$ & $1.7(1.5)$ & -7.29 & 208.2 & 0.123 & $1.66^{\circ}$ \\
Glass & $44.1(1.1)$ & $1.25(1.8)$ & $1.9(1.7)$ & -9.09 & 213.1 & 0.206 & $2.56^{\circ}$ \\
\hline
\end{tabular}




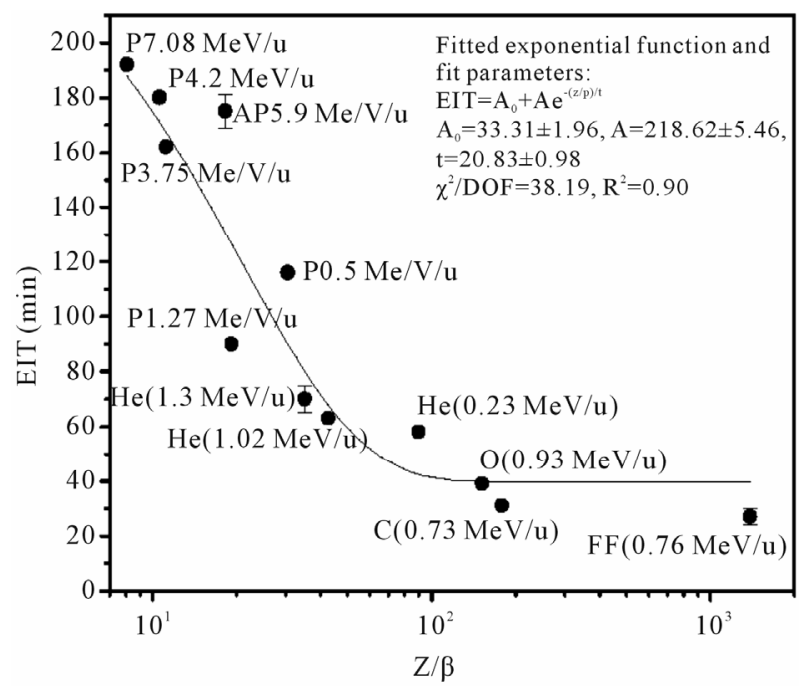

Figure 3. Etch induction time of antiprotons (AP), alpha particles $(1.3 \mathrm{MeV} / \mathrm{u})$ and fission fragments $(\mathrm{FF})$ as a function of $\mathrm{Z} / \beta$. Values of EIT for protons $(0.5 \mathrm{MeV} / \mathrm{u}),{ }^{4} \mathrm{He}(0.23$ and 1.02 $\mathrm{MeV} / \mathrm{u}),{ }^{12} \mathrm{C}$ and ${ }^{16} \mathrm{O}$ ions taken from Khan et al. [19] and for protons $(1.27,3.75$ and $7.08 \mathrm{MeV} / \mathrm{u})$ by Dörschel et al. [20].

Related published data $[19,20]$ is also included in the plot. This is a simple and inexpensive method for identification of particles in composite radiations like cosmic rays. This method can be used in charged particle identification when the effect of etching conditions on EIT is excluded by keeping etching conditions precisely same for tracks of both known and unknown particles.

Precisely controlled and reproducible etching of nuclear tracks at a micrometer scale and below is a requirement that can extend the use of nuclear track detection technique in diverse traditional technologies. It can be effectively useful in fabrication of nanotechnology if we find a way of precisely controlled etching of core of the latent track. Computation supported experiments are required in optimizing the etching procedure for such applications. Microscopic model for chemical etching of latent tracks is recently developed (Rana, 2010) which describe dependence of etchability of tracks on basic observable parameters. Dependence of reduced etch rate or V-function on etching conditions, non-quantified stirring during etching and aging effects of etching agent are discussed. Trustworthy predictions of etched track parameters are possible by discovering a new parameter similar to reduced etch rate but showing negligible dependence on etching conditions. A proposal of such a parameter is made here.

\subsubsection{Annealing of Latent Particle Tracks}

A number of environmental factors affect the formation and stability of etchable tracks in SSNTDs. Among environmental factors, temperature is the most significant because low temperature can decrease the diffusion of displaced atoms in the vicinity of particle tracks whereas higher temperature can increase their diffusion causing partial repair of the radiation damage. In many experiments (e.g. cosmic ray experiments), particle tracks undergo thermal fading due to elevated temperatures which can affect the observed charge and energy spectra of particles. Study of thermal effects on nuclear tracks is very important in view of rapidly increasing practical applications of etched track detectors in different scientific fields including thermal history of earth crust. Study of this process can also give us an insight into the track formation mechanism as it is the reciprocal of track fading process. Annealing Twenty five samples of CR-39, each of $(2 \times 2) \mathrm{cm}^{2}$ area, were irradiated with fission fragments of ${ }^{252} \mathrm{Cf}$. Irradiation was done in air using $2 \pi$ geometry. These irradiated detectors were annealed in a temperature-controlled oven for different time intervals (5 to $30 \mathrm{~min}$.) and temperatures (373 to $448 \mathrm{~K})$. Variation in annealing temperature was not more than $\pm 1 \mathrm{~K}$. For each of the four different temperatures (373, 398, 423 and $448 \mathrm{~K})$, six exposed detectors were annealed for time intervals, 5 to 30 minutes. One detector was exposed but not annealed in order to compare its results with the results of annealed detectors. Tracks of fission fragments were observed after etching these detectors in $6 \mathrm{~N} \mathrm{NaOH}$ at $\left(70^{\circ} \mathrm{C} \pm 1^{\circ} \mathrm{C}\right)$ for 35 minutes. Each detector was observed to contain nearly 150 tracks of fission fragments. Lengths of all the tracks were measured and the mean value of 15 longest tracks was used in the calculation. This was done to reduce the effect of broad spectrum of fission fragments so that annealing effect can be studied precisely. Details were given elsewhere [21-23].

Later on a mathematical formula is derived for annealing of radiation induced damage in solids starting with the empirical equation having a form of the Arrhenius equation [24]. This formula is transformed into a practical relationship in the usable form to fit the experimental track annealing data by making use of a relationship between fractional defect density in the latent track and etched track length. Calculated lengths of fission fragment tracks in annealed CR-39 based on the proposed model are compared with corresponding experimental measurements (our previously published results). Physical meanings of parameters involved in the proposed model are given with appropriate theoretical explanation guided by analysis based on the model fit on track annealing measurements. The results in this paper are useful for a wide spectrum of researchers including cosmic-rays physicists, geologists, nuclear track methodologists and semiconductor/accelerator physicists using ions implantation for doping semiconductors and materials modifications. The final formulation of the model is given, 


$$
\ln r(t, T)=\beta \ln \left[1+\frac{t}{t_{o}} \exp \left(-\frac{E_{a}}{k T}\right)\right] .
$$

Model-fit analysis of the parameters of the proposed model has made clear that $E_{a}$ (activation energy of annealing) and $t_{o}$ (characteristic annealing time) show weak dependence on annealing temperature while the dimensionless parameter $\beta$ shows strong nonlinear dependence on annealing temperature. The significance of the parameter $\beta$ for variable temperature annealing of nuclear tracks is discussed. Future extension of this work might be the investigation of the dependence of the parameter $\beta$ on properties of detector or target materials and track forming particles. Figure 4 shows the quality of fit between experiments and proposed model.

\subsubsection{Nuclear Interactions}

\subsubsection{Nuclear Fission and Fragmentation}

Even after extensive investigations for decades, a unified view about structure of nucleus is still lacked. As nuclear track detectors offer a unique opportunity to study the heavy ion interactions like fission and fragmentation, the behaviour and decay channels of highly excited heavy projectile and target nuclei have been studied. Several investigations were carried out regarding structure and dynamicity of heavy nuclei at PINSTECH using SSNTDs. A number of nuclear reactions were studied using SSNTDs. A few representative examples [25-27] are discussed here in a bit detail to convey the research theme. In one investigation, Khan et al. [25]

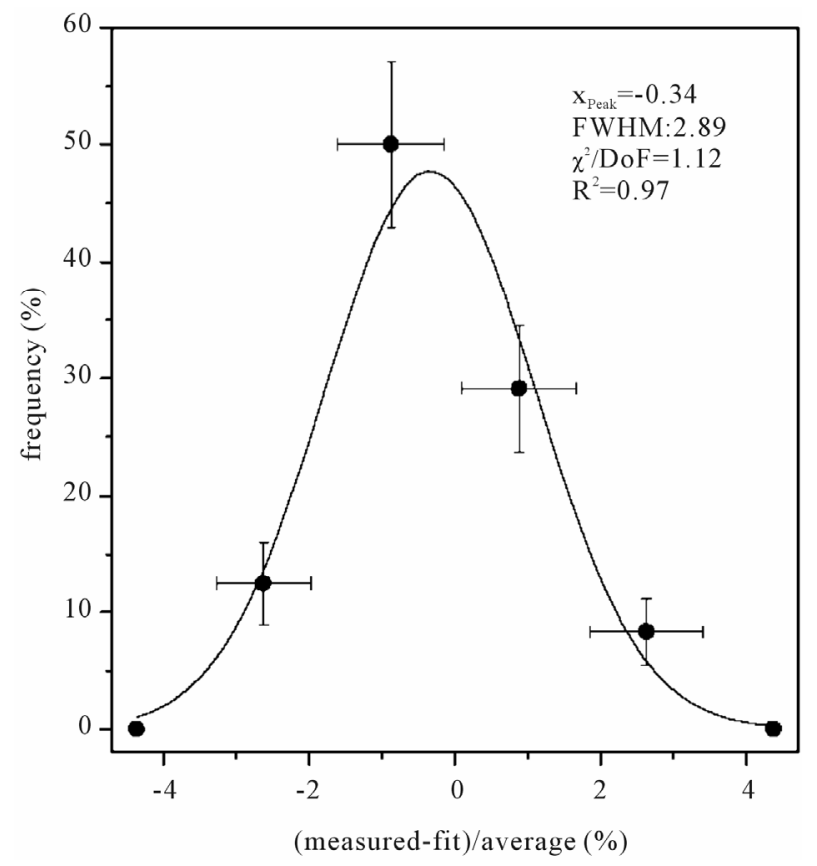

Figure 4. Deviations of model predictions from corresponding experimental results. studied the heavy ion interactions of (14.0 MeV/u) $\mathrm{Pb}+$ $\mathrm{Au}$ using two threshold detectors, mica and CN-85. Target-detectors assemblies were exposed to a beam of 14.0 $\mathrm{MeV} / \mathrm{u} \mathrm{Pb}$ ions with the fluence of $1.5 \times 10^{6} \mathrm{~cm}^{2}$ at GSI, Darmstadt, Germany. They have shown interesting results of partial cross sections of different multiplicities of reaction products. These results are plotted in Figure 5 [25] which shows that a significant number of intermediate mass fragments were produced along with the heavy fragments. In a similar investigation, Shahzad et al. [26] have found the evidence of sequential fission has been found in the heavy-ion reaction $(16.7 \mathrm{MeV} / \mathrm{u}){ }^{238} \mathrm{U}+$ ${ }^{\text {nat }} \mathrm{Au}$ using muscovite mica placed in a $2 \pi$-geometry [26]. They also investigated the emission of light reactions products in these reactions. Qureshi et al. [28] (1988) reported a two step reaction mechanism of a four-fragment exit channel of interactions of $1050 \mathrm{MeV}{ }^{84} \mathrm{Kr}$ projectiles with natural uranium targets.

A different but similar way of investigating the nucleus structure is the measurement of fragmentation cross sections of nuclei interacting at relativistic energies. A number of investigations have been carried out in last 10 years by PINSTECH group independently or in collaboration with Bologna University group to understand fragmentation behaviour of relativistic nuclei on different targets [29-38]. Two representative investigations one related to calibration of CR-39 detectors for identification of fragments and other about fragmentation cross sections of relativistic $\mathrm{Pb}$ projectiles are briefly described to highlight the theme of these investigations. Target detector assemblies employing CR-39 Track Detectors with $\mathrm{Cu}$ and CR-39 targets were exposed to $158 \mathrm{~A} \mathrm{GeV}$ $\mathrm{Pb}$ projectiles at the CERN-SPS experimental facility. The exposure of stack was performed at normal incidence with a fluence of about 1500 ions $/ \mathrm{cm}^{2}$. For the

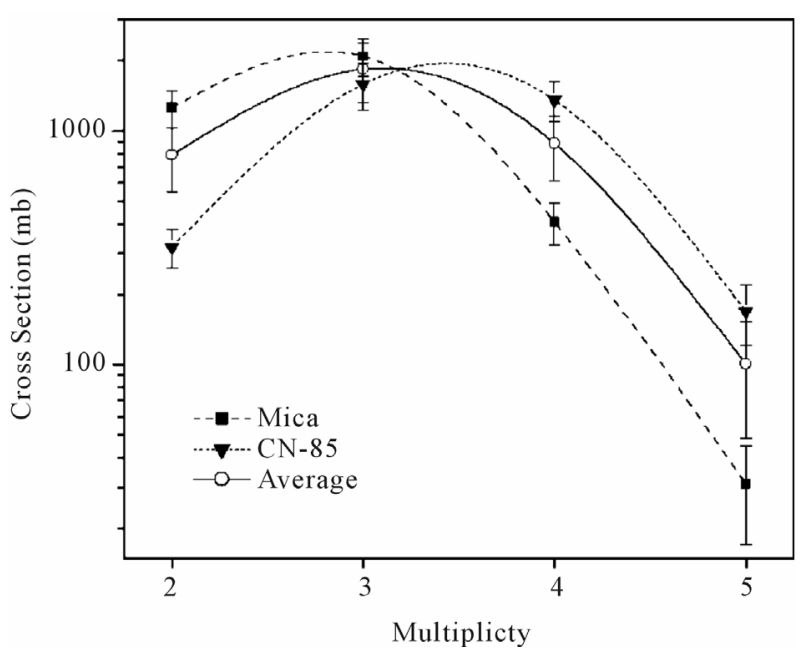

Figure 5. Partial cross sections of different multiplicities measured using two detectors. Averages of corresponding measurements also shown. 
stack with the $\mathrm{Cu}$ target, the lengths of etched cones on one face of the CR-39 detectors (before and after the target) were measured.

Using these measurements and charge identification methodology in CR-39 track detectors, total and partial charge changing cross sections of $158 \mathrm{~A} \mathrm{GeV} \mathrm{Pb}$ projectiles on $\mathrm{Cu}$ and CR-39 targets are determined in the charge region $63 \leq Z \leq 82$. The possibilities of presence and absence of odd-even effect in measured partial charge changing cross sections of $158 \mathrm{~A} \mathrm{GeV} \mathrm{Pb}$ ions for $\mathrm{Cu}$ and CR-39 targets are described. The charge resolution $\left(\sigma_{\mathrm{Z}}\right)$ achieved in the present experiment is $\sim 0.18 \mathrm{e}$ 0.21 e. Recent representative results are shown in Figure 6. This figure shows the measured partial chargechanging cross sections along with uncertainties for 158 $\mathrm{A} \mathrm{GeV} \mathrm{Pb}$ ions in $\mathrm{Cu}$ and $\mathrm{CR}-39$ targets are shown. Published partial charge-changing cross sections [31,39] for identical reactions are also shown. Our previous results of partial charge-changing cross sections of $158 \mathrm{~A} \mathrm{GeV}$ $\mathrm{Pb}$ ions in $\mathrm{Cu}$ are more systematic compared with the case of CR-39 target, which is a compound target [30].

It should also be noticed that incident beam for $\mathrm{Cu}$ target was more pure $\mathrm{Pb}$ ion beam compared with that for CR-39. Errors in charge-changing cross sections for $\mathrm{Cu}$ target are between $3 \%$ and $18 \%$ for proton pickup whereas for CR-39 target they are between 3\% and 22\%. Our analysis [30] showed that there can be two possibilities about fragmentation of a highly excited nucleus. In one case, fragmentation products depend on magnitude of excitation energy whereas in other when it depends on both magnitude and nature of excitation. The second possibility is true in case of fragmentation of fullerene(s) [40]. Fullerene is a cluster of atoms whereas nucleus is a cluster of nucleons. Although bonding nature of constituents of nucleus and fullerene is completely different, fragmentation of these two objects might have similarities. It is difficult to understand nature of excitation of a highly excited nucleus due to involvement of a large number of internal degrees of freedom, even some of them are not well-understood yet [41]. Dotted vertical lines are drawn in Figure 6 for even values of $\Delta Z$ to make clear the presence or absence of odd-even effect. Our results show that structure of odd-even effect in fragmentation charge-change spectrum is quite complex and is observed in our results partly as only Z-evenness was measurable in our experiments. So our experiments were only able to observe one degree of freedom of a 2-fold (proton and neutron numbers) complex structure [42]. For values $\Delta \mathrm{Z}=9,10$ and 11 , clear opposite trend for odd-even effect is observed for our measurements of copper and CR-39 targets.

\subsubsection{Antiproton Induced Reactions}

PINSTECH group was the first to show antiproton

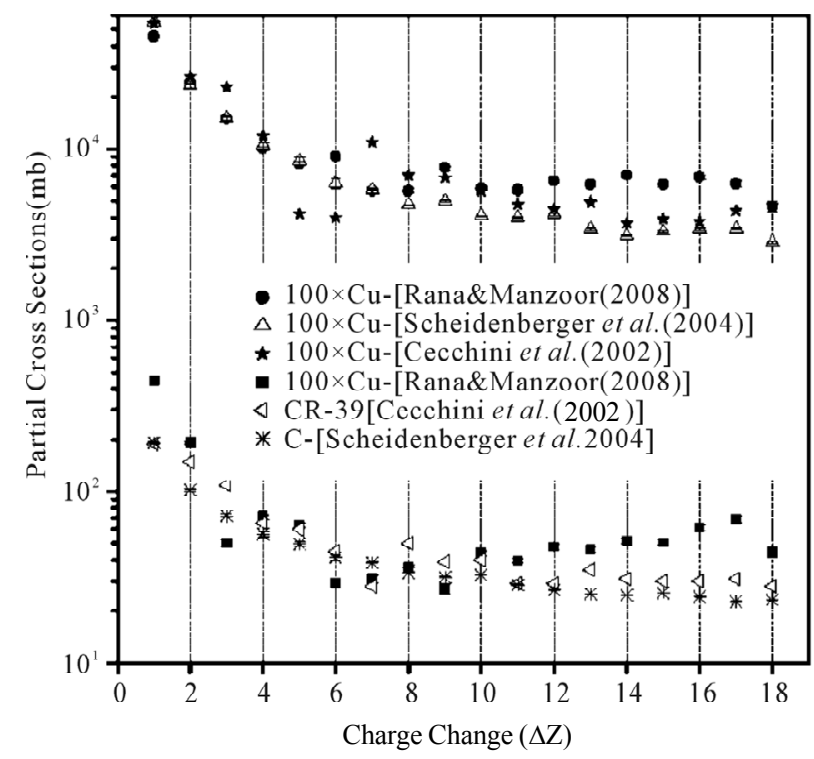

Figure 6. Partial charge-changing cross sections for $158 \mathrm{~A}$ $\mathrm{GeV} \mathrm{Pb}$ ions on $\mathrm{Cu}$ and $\mathrm{CR}-39$ targets as a function of charge change $\Delta \mathrm{Z}$. Comparison is also made with related published results.

tracks in track detectors CR-39 [43]. We also measured light particles produced after annihilation of antiprotons in light nuclei (H, C and O) [44]. For this investigation, CR-39 detectors were exposed to $5.9 \mathrm{MeV}$ antiprotons at CERN. After exposure, the detectors were etched in $6 \mathrm{~N}$ $\mathrm{NaOH}$ solution at $70^{\circ} \mathrm{C}$. Antiproton tracks were revealed after 135 minutes of etching and their further growth was studied as a function of etching time. Antiproton track diameter and track density were measured after each of several etching steps leading to the total etching time of 290 minutes. Figure 7 shows the SEM of the antiproton tracks in CR-39 whereas bottom plot shows the mean track diameter as a function of etching time. The timeintercept in this plot is defined as the etch induction time (EIT). The value of etch induction time for $5.9 \mathrm{MeV}$ antiprotons in CR-39 under above mentioned etching condition is determined to be 85 minutes.

Figure 8 shows the distribution of track lengths of particles produced after annihilation of $5.9 \mathrm{MeV}$ antiprotons in light nuclei in CR-39 target (Rana et al., 2006). Our investigations have found important information about antiproton tracks. Tracks of $5.9 \mathrm{MeV}$ antiprotons in CR-39 detector are found to bee pit like in shape. The mean diameter of antiproton tracks is $2.05 \pm 0.45 \mu \mathrm{m}$ after 185 minutes of etching in $6 \mathrm{~N} \mathrm{NaOH}$ at $70^{\circ} \mathrm{C}$. Diameter of antiproton tracks had a wide distribution with uncertainty of almost $22 \%$. Lengths of $5.9 \mathrm{MeV}$ antiproton tracks were not precisely measurable and tracks seemed to be partially etched at depth. The track density of antiprotons decreases with etching. It can be due to the discontinuous nature of tracks and annihilation of anti- 


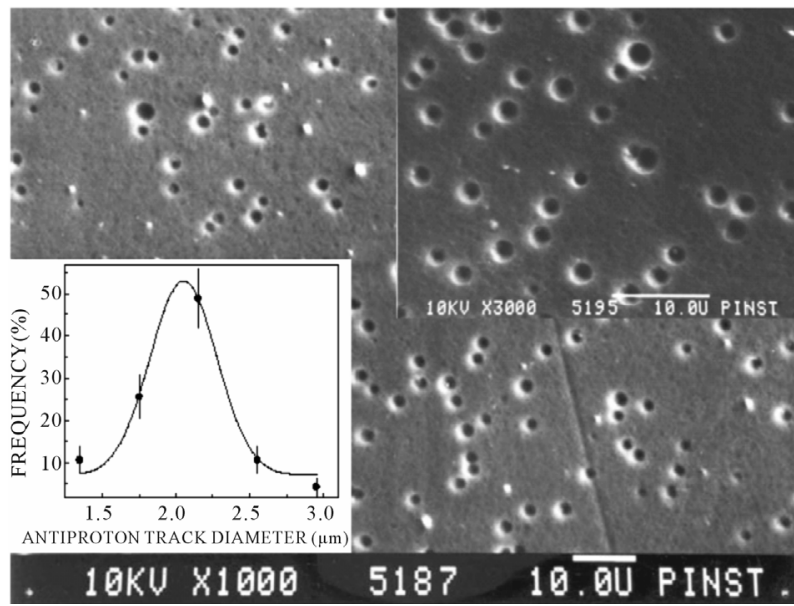

Figure 7. Scanning electron microscopy measurements of 5.9 $\mathrm{MeV}$ antiproton tracks in CR-39 after etching in $6 \mathrm{~N} \mathrm{NaOH}$ solution at $70^{\circ} \mathrm{C}$ for 290 minutes. Top inset is antiproton tracks at higher magnification. Bottom inset is diametric distribution of antiproton tracks.

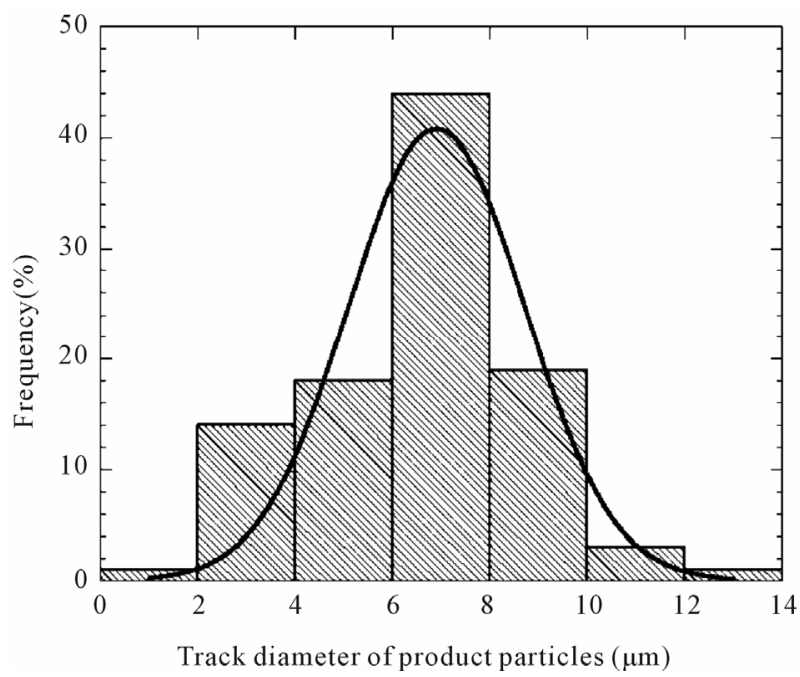

Figure 8. Distribution of track diameters of particles produced after annihilation of $5.9 \mathrm{MeV}$ antiprotons in light nuclei in CR-39 target.

protons with constituents of CR-39 detector. Other cause of track density decrease with etching is the removal of large angle (with normal to CR-39) tracks formed by particles produced after annihilation of antiprotons in target nuclei in CR-39 near the end of antiproton range. Our limited experimental observations of antiproton tracks in CR-39 suggest that tracks of antiparticles (annihilated near the end of their range) are similar to those of particles with the difference that tracks of other particles formed after annihilation of antiparticles in the nuclei in target material will be present. For $5.9 \mathrm{MeV}$ antiprotons beam, stairs-type design of the stack, as shown in Figure 9, would have been very useful. It was easy to extract much more information about antiproton tracks using

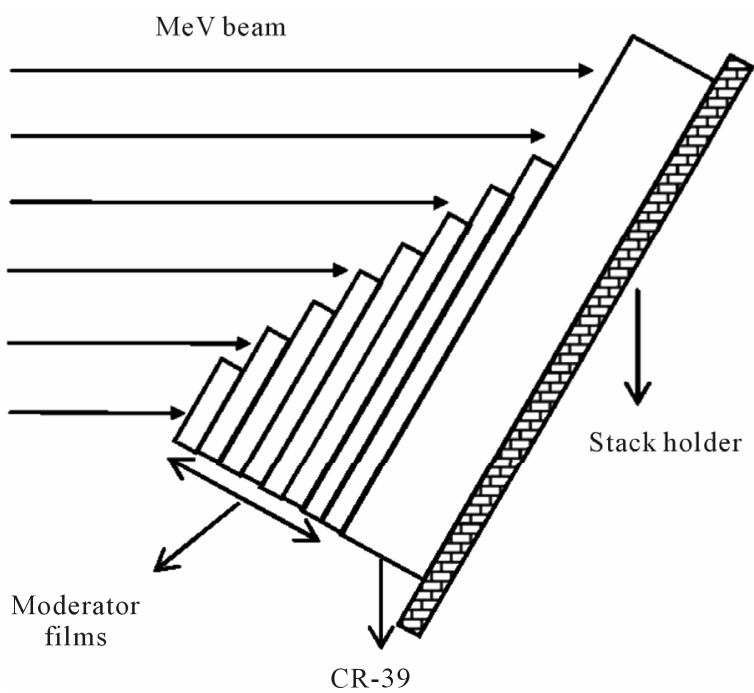

Figure 9. A staircase-type design for studies of characteristics of antiproton tracks and antiproton annihilation in target nuclei. A stack of moderator thin layers (like mylar films) with variable length is used to get spectrum of antiproton energies at the detector or target surface.

this design as it was possible to observe tracks of antiprotons with a range of energies etched under the same conditions. This type of design is also useful to study annihilation of antiprotons in a target by depositing/ placing it between moderator and track detector assembly shown in Figure 9.

\subsubsection{Pion Induced Nuclear Reactions}

A number of investigations were carried out on fission induced by pions of distinctive energies $(80,100,500$, 672,1068 and $1665 \mathrm{MeV}$ ) in different targets from Fe to $\mathrm{U}$, for example [45-51]. Exposures were made at Brookhaven National Laboratory, US. Exposure details are given in Figure 10. It is now well established that real or virtual pi mesons play an important role in several nuclear transformations or reactions induced by strong nuclear force, especially at low and intermediate energies [52,53]. Khan et al. [45] started pion induced fission related research in Pakistan (in collaboration with University of Colorado, USA) with the fission studies of natural uranium induced by 80 and $100 \mathrm{MeV}$ positive and negative pions using SSNTDs. Later on, pion induced reactions in several targets including $\mathrm{Ta}, \mathrm{Eu}, \mathrm{Sn}$, $\mathrm{Zr}, \mathrm{Cu}, \mathrm{Au}$ and $\mathrm{Bi}$ were studied Khan et al. [46]. Explanatory details of these studies are given Khan et al. [47] and Peterson et al. [48]. Yasin et al. [49] have compared experimentally measurements of negative pion induced fission cross sections of gold and bismuth targets in previous studies with corresponding calculations using the code CEM95 $[54,55]$.

They have found good agreement between measurements and corresponding calculations. Major theme of 
hithlt

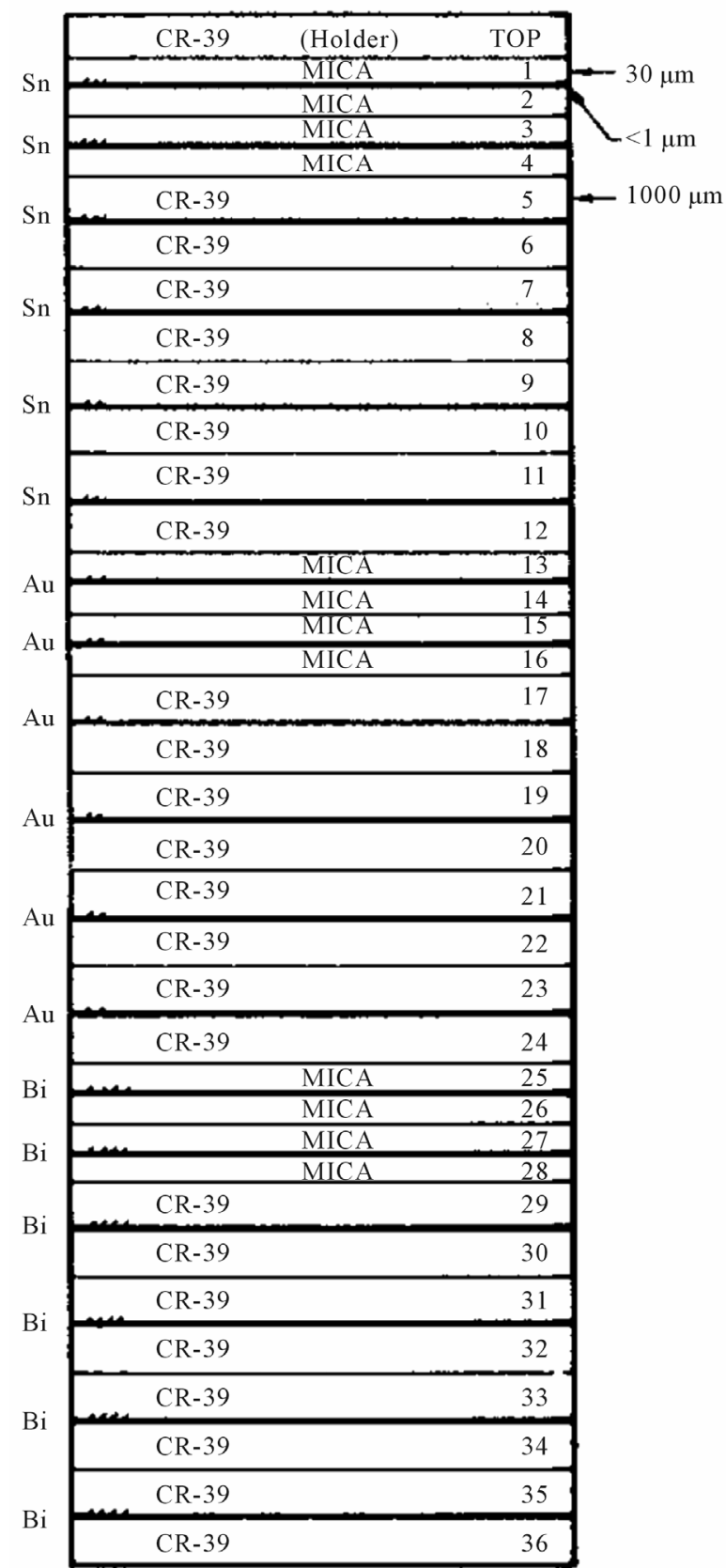

Figure 10. Schematic showing the stack used in the present studies. The stack was exposed to the pion beam at Brookhaven National Laboratory, US.

above mentioned experiments was to study mass and energy dependence of pion-induced fission. Fission cross sections of various targets, induced by (a) $80 \mathrm{MeV}$ positive pions and (b) $80 \mathrm{MeV}$ negative pions, measured in above mentioned studies are presented in Figure 11 $[45-51,56]$. They have set up a universal dependence of binary fission for both beam charges and energies below

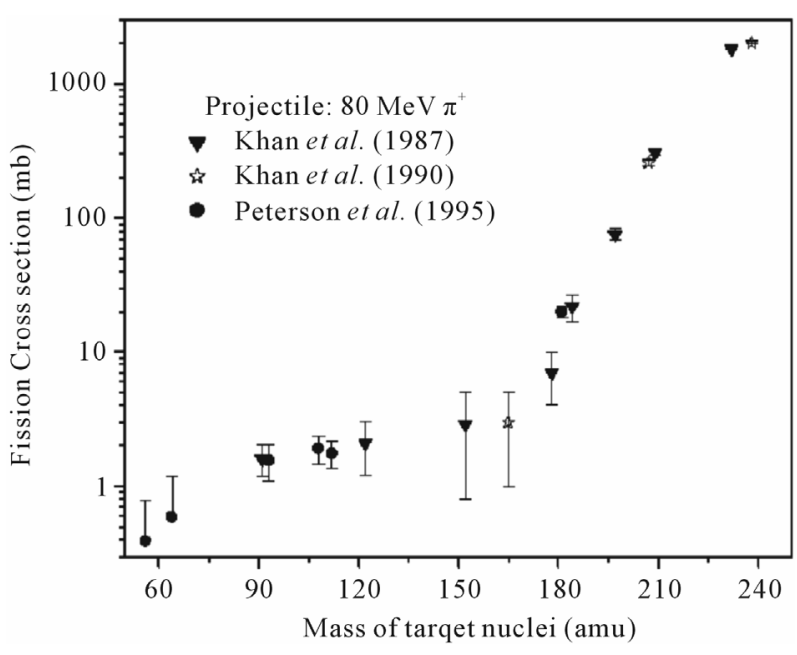

(a)

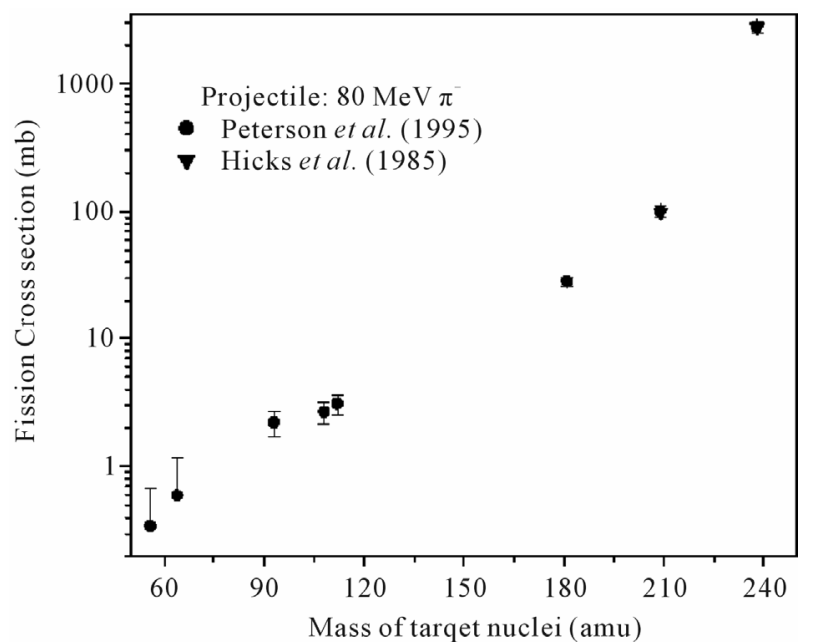

(b)

Figure 11. Fission cross sections of various targets studied using SSNTDs by PINSTECH group in collaboration with the research team of Peterson et al. at University of Colorado, USA. In plot (a), projectile was positive pion whereas in (b) projectile was negative pion.

delta resonance. In modeling of experimental results, a single parameterization was able to describe the pion induced fission for a wide range of projectile energy and target mass.

\subsubsection{Nuclear Geology}

\subsubsection{Earthquake Prediction}

Prediction of an earthquake has been a great challenge faced by the humanity. Difficulties in earthquake predicttion arise from a number of parameters involved with very high levels of uncertainties in relating intensities of poorly understood processes going on very deep from the earth's surface in the mantle and rupture dynamics of earth's crust, especially along the fault lines. Only a set of phenomenal models can explain the origin and evolution 
earthquakes, and their precursors which are impor- tant in prediction of time, intensity and location of earthquake. One possible precursor of an earthquake is abnormally high and inconsistent emanation of radon resulted from the decay of natural uranium in earth's crust. This possibility was investigated by SSNTDs group at PINSTECH. The group conducted a set of ex- periments employing CR-39 and CN-85 detectors for monitoring the exhalation of radon at appropriate stations at a known distance from each other.

Track detectors were inside steel tubes which were at the bottom of a borehole about $50 \mathrm{~cm}$ deep from the earth's surface. Exposure period was from 24 hours to a few weeks, but more appropriate time of exposure was 24 hours after which old detectors were replaced by new ones. The experimental arrangement of monitoring the radon for earthquake prediction is shown in Figure 12. Details of some experiments are given in a comprehendsive study about use of SSNTDs as a geological/geophysical tool which was conducted by Khan and Qureshi [57]. Leading results of this study are shown in Figure 13. It was possible to correlate abnormal exhalation of radon with occurrence of earthquake with some uncertainties visible in the figure. Although the principle of the method adopted has a scientific basis, but a lot more work is required to bring in precision and reliability. Actually, huge efforts are needed to cover a considerable area with ongoing experiments for long time to observe the earthquake at investigated sites. A related requirement is to map the locations of geological faults required for site selection for sensitive and/or big structures like dams and reactors, especially nuclear reactors. Major concern about nuclear technology is safety. Safety failure can be disastrous. Earthquakes are a reality and are still an un-predictable to challenge the safety. Countries with nuclear technology have to consider earthquake factor in maintaining their nuclear technology, and related facilities and future plans [58].

\subsubsection{Fission Track Dating}

Fission track dating (FDT) is a radiometric technique which makes use of analysis of fission fragment tracks in minerals. These tracks are due to fission fragments of uranium in minerals formed long back time in the history. This is a simple technique but has played a significant role in unraveling the thermal history of continental earth's crust. It also has an ability to shine light on other hidden geophysical, archeological, anthropological and cosmological facts [59-63]. Scientists at PINSTECH have developed extensive expertise in FDT. They employed FDT in investigating samples from various areas of Pakistan attempting to understand the overall geology of Pakistan [64-69]. Their studies are helpful in locating the areas as potential sources for various minerals. Paki-

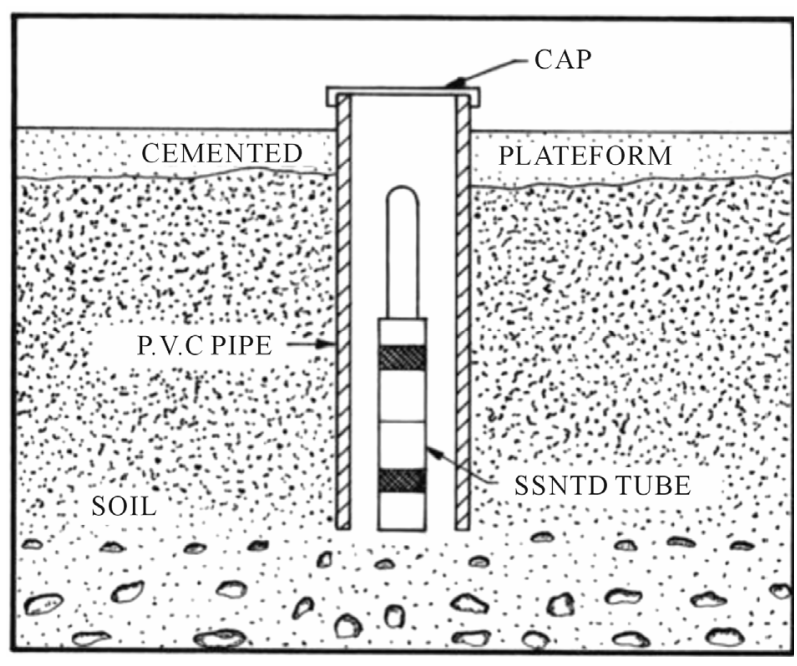

Figure 12. The experimental arrangement of monitoring the radon for earthquake prediction.

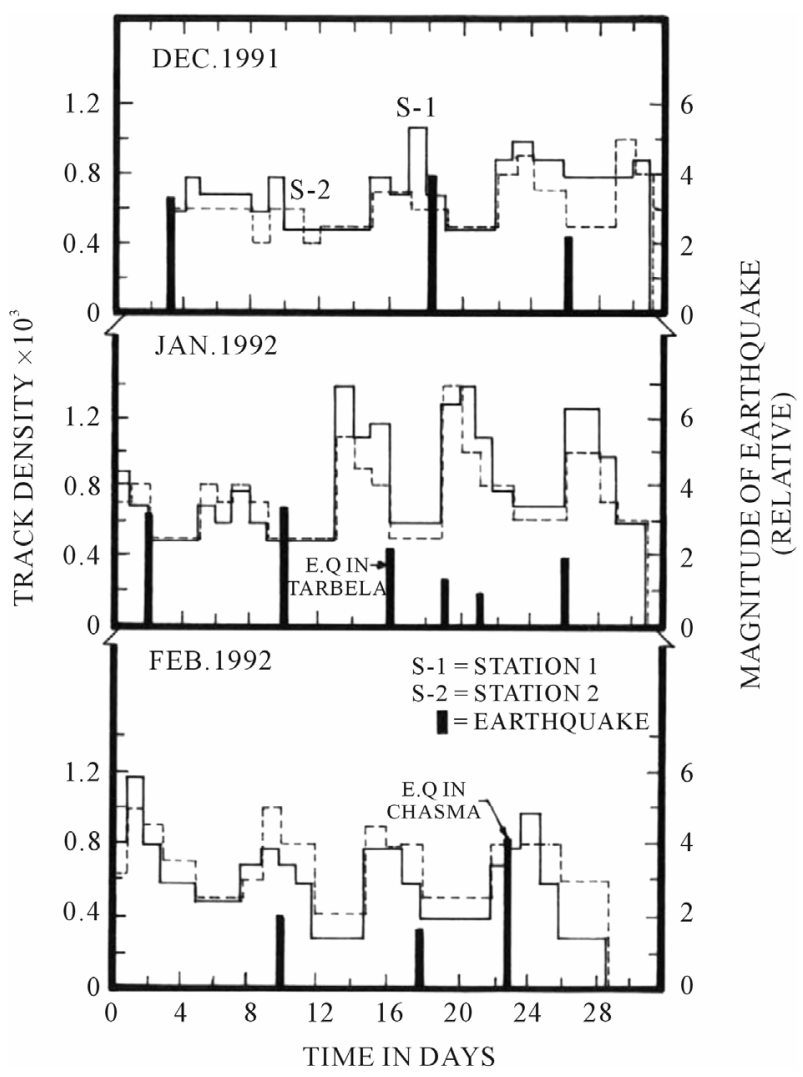

Figure 13. Radon measurement results for prediction of earthquake by Khan and Qureshi (1994). Results of two radon measurement stations are shown.

stan has a promising geological landscape for oil and gas reserves. The oil generation and maturity depends on thermal history of the landscape. The time-temperature window suitable for oil and gas generation can be determined using FDT of apatite. The possibility of exploration of oil and gas using FDT is under plan. 


\subsubsection{Environmental Radiations}

\subsubsection{Personal and Environmental Radon Dosimetry}

Use of SSNTDs for radon dosimetery is the most flourishing area around the globe over the past more than 20 years [70]. In Pakistan, there have been three main groups working on the use of SSNTDs for radon measurement by Jamil and colleagues [71-76], Matiullah and colleagues [77-83] and Tufail and colleagues [84,85]. These groups worked on measurement of radon, thoron and progenies and effective doses to different relevant communities around the Pakistan territory. They have done a great job in starting and developing a radon map of Pakistan which is useful in a number of applications. Due to limited resources and difficulties in access and maintaining experiment in remote areas, radon map is still far from completion. Active efforts are continued in

\section{this direction.}

There a few types of SSNTDs based radon dosimeters in use. Most common of them are pen type dosimeter, box type dosimeter, KDC type dosimeter, bare type dosimeter and tube type dosimeter. Different dosimeters fit for radon measurement in different environments. One has to consider which type of dosimeter is suitable for a specific location and research motivation. Different dosimeters in use are sketched in Figure 14. A standard method for installation of these dosimeters for radon monitoring of an ore sample in a laboratory is shown in Figure 15. Relative performance of different dosimeters mentioned above has been discussed by Jamil et al. [74,75]. Table 3 documents the inter-calibration factors for passive dosimeters based on CR-39 and CN-85 detectors. These calibrations are required for conversion of track densities in passive dosimeters into radon doses.

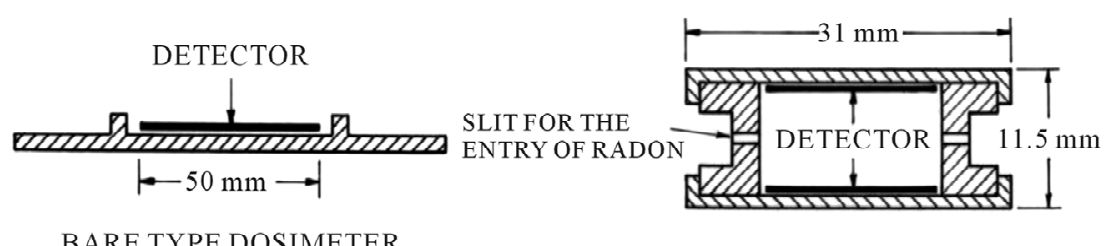

BARE TYPE DOSIMETER

BOX TYPE DOSIMETER

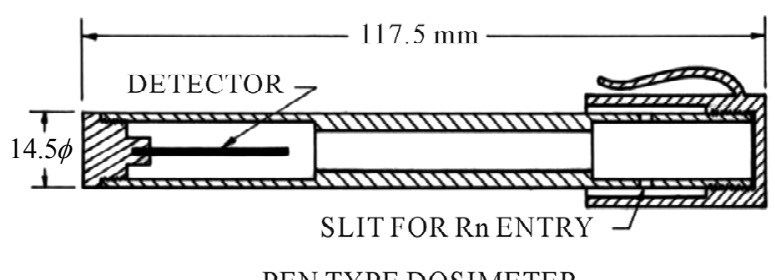

PEN TYPE DOSIMETER

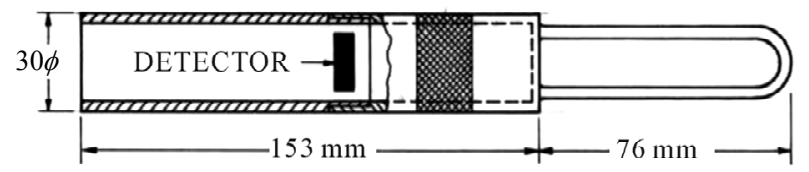

TURE TYPE DOSIMETER

Figure 14. Schematic drawings depicting interior sketches of dosimeters in use at different institutes and universities in Pakistan.

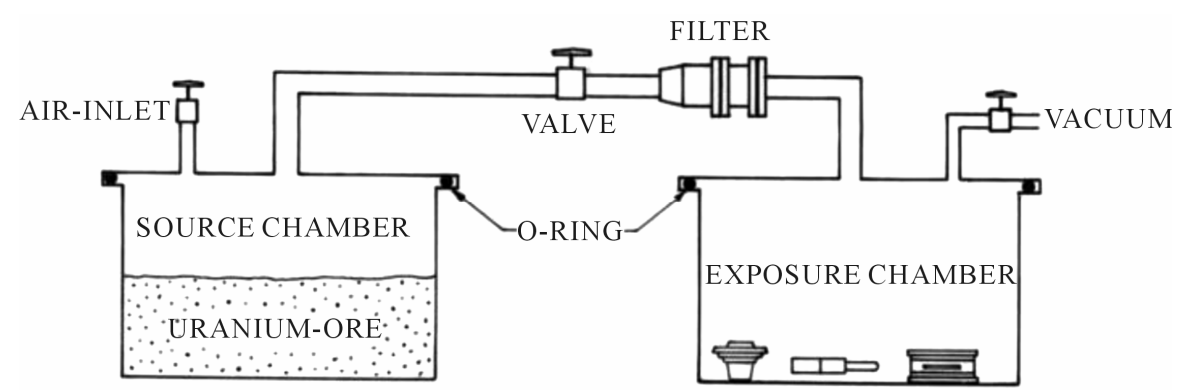

Figure 15. A typical experimental set up for radon monitoring using passive dosimeters. 
Table 3. Calibration factors for passive dosimeters based on CR-39 and CN-85 detectors (Jamil et al. [74,75]).

\begin{tabular}{lcc}
\hline Dosimeter & $\begin{array}{c}\mathbf{C R}-39 \text { dosimeters } \\
\left(\mathbf{B q} \cdot \mathbf{m}^{-3} \text { /track density }\right)\end{array}$ & $\begin{array}{c}\mathbf{C N}-85 \text { dosimeters } \\
\left(\mathbf{B q} \cdot \mathbf{m}^{-3} / \text { track density }\right)\end{array}$ \\
\hline Box-type & $(78.2 \pm 8.6) \times 10^{3}$ & $(70.5 \pm 8.1) \times 10^{3}$ \\
Pen-type & $(27.4 \pm 3.3) \times 10^{3}$ & $(22.8 \pm 2.7) \times 10^{3}$ \\
Tube-type & $(142.4 \pm 14.3) \times 10^{3}$ & $(129.0 \pm 16.7) \times 10^{3}$ \\
KDC-type & $(204.2 \pm 24.5) \times 10^{3}$ & $(182.6 \pm 22.1) \times 10^{3}$ \\
Bare-type & $(273.2 \pm 32.7) \times 10^{3}$ & $(248.2 \pm 32.2) \times 10^{3}$ \\
\hline
\end{tabular}

\subsubsection{Neutron Dosimetry}

Neutrons are very important specie of particles involved in nuclear technology. Neutron dosimetery for individuals working on nuclear reactors is extremely important task. SSNTDs have shown a little success in neutron dosimetery as neutrons are not directly detectable by SSNTDs. Neutron detection by SSNTDs is possible only indirectly through measurement of recoil tracks. There are serious difficulties in revealing, identification and measurement of recoil tracks, especially below the surface. A number of attempts have been made by PINSTECH scientists to development neutron detection and measurement using SSNTDs [76-81]. In recent investigations by Malik et al. [80] and Khan et al. [81], they have developed experimental method for determination of neutron fluence using SSNTDs. CR-39 detectors were exposed to neutrons from the $14.0 \mathrm{MeV}$ neutron generator at PINSTECH with fluences from 107 to 1010 $\mathrm{n} \cdot \mathrm{cm}^{-2}$. Exposed detectors were etched for $10 \mathrm{~min}$ in $6 \mathrm{~N}$ $\mathrm{NaOH}$ at $70.0^{\circ} \mathrm{C} \pm 1.0^{\circ} \mathrm{C}$ and the transmittance of UV radiation was measured using a spectrophotometer. This procedure was continued until a minimum of transmittance was reached. An exponential decrease of the transmittance was observed with respect to the increasing etching time interval in each neutron exposed detector. The observed linear relationship between the transmittance decay constant and neutron fluence can be used as a calibration for measuring the unknown fluence of 14.0 $\mathrm{MeV}$ neutrons [80,81].

\subsubsection{Stable and Radionuclides in Drinking Water and Other Environment}

A number of investigations have been carried out at PINSTECH aimed at determination of stable and radioanuclides in drinking water and other eatables, material particulates, quantification of industrial air pollutants using FDT, neutron activation and nuclear track microfilters [82-84]. Quantification of uranium in drinking water can be helpful for providing guidelines to the general public and necessary protective measures. Akram et al. [84] used FDT for the estimation of the uranium concentration in drinking water collected from natural springs of Muzaffarabad and hilly areas of Reshian, Azad Kashmir. In this study, uranium concentration in water samples from the Muzaffarabad and Reshian area varied from $0.03 \pm 0.01 \mu \mathrm{g} \cdot \mathrm{L}^{-1}$ to $6.67 \pm 0.14 \mu \mathrm{g} \cdot \mathrm{L}^{-1}$ which are less than the maximum permissible levels of 9 $30 \mu \mathrm{g} \cdot \mathrm{L}^{-1}$. In another recent investigation, Husaini et al. [85] studied ceramics, pulp/paper and textile/yarn effluxents to estimate the removal efficiency of the pollutants by the use of nuclear track membrane. Flux, temperature, applied pressure, flow rates, density, concentration of the effluents and their interrelationships were explained. It was demonstrated that the pollution parameters had been reduced in post filtration effluents.

\subsubsection{Nanotechnology Related Studies}

Nanotechnology is expected to create many new materials and devices with a wide range of novel applications in medicine, electronics and energy sectors. A set of recent extensive investigations by Fink et al. [86], Apel et al. [87] and Spohr [88] have analyzed and explained the use of nuclear tracks in micro and nanofabrication. They have addressed the problems involved in this method, especially controlled etching of ion track nanopores. A new activity is started by Dr. S. Karim at PINSTECH which is making use of ion tracks for nanofabrication in collaboration with Institute of Material and Earth Science, Darmstadt University of Technology, Darmstadt, Germany, and GSI Materials Research Department, GSI Darmstadt, Germany. Karim et al. have started publishing their laboratory research [89-93].

In a recent investigation, Karim et al. [89] have studied the diameter dependence of failure current density of gold nanowires. They have fabricated single nanowires with diameters ranging from 80 to $720 \mathrm{~nm}$ and length 30 $\mu \mathrm{m}$ in ion track-etched single-pore polycarbonate (Makrofol-N) membranes. The investigated the maximum current density keeping the wires embedded in the polymer matrix by ramping up the current until failure. The maximum current density increased with decrease in diameter of the nanowire and the wires with a diameter of $80 \mathrm{~nm}$ survived the current density of $1.2 \times 10^{12}$ $\mathrm{A} \cdot \mathrm{m}^{-2}$ before failure. The setup used for electrically contacting single wires in experiments by Karim et al. is shown in Figure 16. Figure 17 shows the scanning electron microscopy image of freestanding gold nanowires after liberating from polycarbonate templates. This figure shows clear demonstration of the fact that the fabricated wires possessed the cylindrical shape with uniform diameter, and smooth and homogeneous contours along their complete length.

\section{INTERNATIONAL COLLABORATIONS}

Major nuclear tracks based international research 


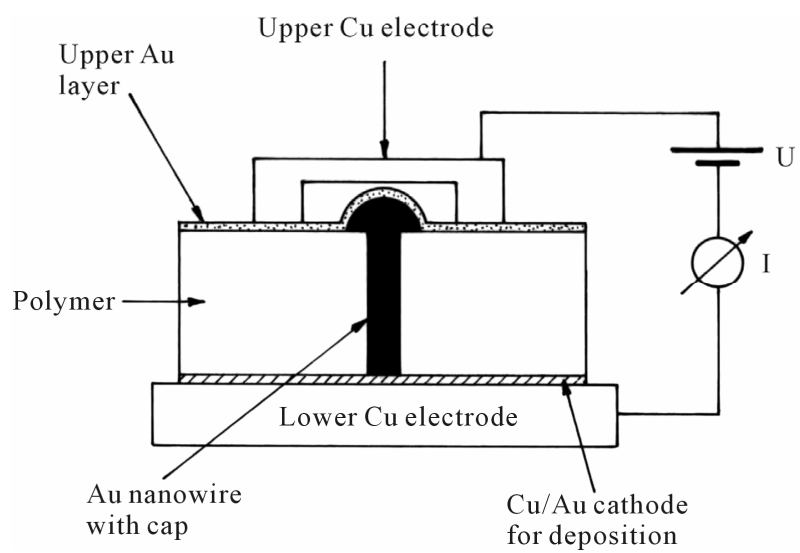

Figure 16. Experimental setup used by Karim et al. [89] for measurement of failure current density of gold nanowires. $U$ and I stands for voltage and current measurements.

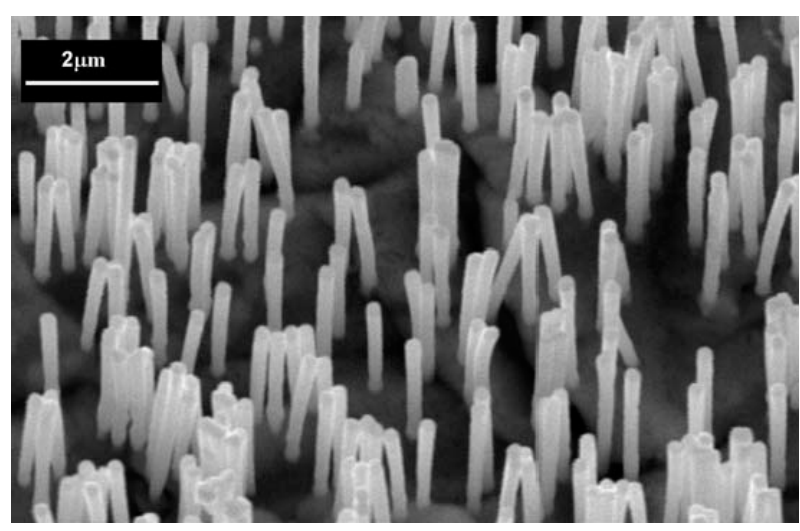

Figure 17. Scanning electron microscopy image of free standing gold anowires fabricated in polycarbonate Makrofol-N membrane by Karim et al. [89].

collaborations were made by the original SSNTDs Laboratory, PINSTECH. This laboratory was extended as Ra- diation Physics Division (RPD) of PINSTECH in 1992. A series of experiments using radio-chemistry and trackdetection techniques were carried out in collaboration with the Philipps University, Marburg, Germany. Experiments on interactions of relativistic ${ }^{16} \mathrm{O}$ and ${ }^{19} \mathrm{~F}$ ions were studied in collaboration with the Joint Institute of Nuclear Research, Dubna, Russia. Measurements of pion induced fission cross sections were made at RPD using SSNTDs as a joint research effort with The Clinton P. Anderson Meson Physics Facility (LAMPF) and Brookhaven National Laboratory (BNL), USA. Positive and negative pions of energies 500,672, $1068 \& 1665 \mathrm{MeV}$ were used in this research. Fragmentation of ultrarelativistic $158 \mathrm{AGeV}{ }^{208} \mathrm{~Pb}$ was studied on different targets $\mathrm{Al}, \mathrm{Cu}, \mathrm{Bi}$ and $\mathrm{Pb}$ targets using PARMA CR-39 detectors. RPD participated in Monopole, Astrophysics and Cosmic Ray Observatory MACRO and Search for Light Magnetic Monopoles (SLIM) collaborations. Interactions of 5.9 MeV antiprotons were studied using CR-39 detectors.
Exposures of target-detector assemblies were made at Low Energy Antiproton Ring (LEAR) facility of CERN, Switzerland.

\section{EXPERIENCE LESSONS, MERITS, DEMERITS AND CHALLENGES}

There are several lessons from the success story of Pakistani research on nuclear tracks and their applications. Operation and maintenance of sophisticated electronics is quite difficult in developing and underdeveloped countries. So, radiation detection and measurement systems with sophisticated electronics as integrated parts are not suitable for broad use in developing countries. An appropriate combination of low cost nuclear track detection systems and sophisticated electronic systems can serve the needs in almost all fields ranging from active nuclear technology to just simple radiation measurements. Offline measurements and analysis is another parameter fit for developing countries. This feature provides the possibility to scientific community in developing countries for participation in international experiments (like facilities at CERN, Switzerland) and in other collaborations like MACRO and SLIM.

Studies related to SSNTDs and their applications are of multidisciplinary nature. The multidisciplinary feature along with low cost and simplicity of the technique make it especially suitable for student research projects at graduate and postgraduate levels in various departments at universities including Physics, Chemistry, Health Sciences and Geosciences. This possibility was exploited in a number of universities and colleges in Pakistan. Some of these universities and colleges were in small cities like Dera Ismail Khan and Multan. Similar developments have also been made some other Asian countries. This experience can be further employed in similar situations around the globe to provide the chance of participation in $\mathrm{R} \& \mathrm{D}$ to student and teaching communities in other developing countries.

Key merits of nuclear track detection include simple and small geometry, threshold for detection, low cost, single particle detection and temporal integration of radiation exposure. These features have specific uses. Due to temporal integration, these detectors offer special benefit in recording rare events like magnetic monopoles. SSNTDs need no online system, so experiments with these detectors can be setup in mountains or areas which are inaccessible for a part of the year due to extreme seasonal conditions. In the same way the detection threshold of track detectors can be utilized for the measurement of specific radiations in multi radiation environments. Nuclear technology and cosmic rays are examples of such environments. Demerits include lack of real time information of radiation exposure, dependence 
of charge and energy resolution of incident particles on etching procedure and conditions and poor understanding of formation of latent tracks and their chemical etching.

Defect structure of latent tracks and their chemical etching are challenges of fundamental importance in SSNTDS and their advanced understanding would help in further extension of their applications in different disciplines of science and technology. It should be investigated in a more general sense what controls nuclear track formation in solids. It would help in development of more efficient radiation discriminatory detectors usable in nuclear technology, cosmic-rays, geosciences and environmental radiation monitoring. Precisely controlled and reproducible etching of nuclear tracks at a micrometer scale and below is a requirement that can extend the use of nuclear track detection technique in diverse traditional technologies. It can be effectively useful in fabriccation of nanotechnology if we find a way of precisely controlled etching of core of the latent track. Computation supported experiments are required in optimizing the etching procedure for such applications. The field of SSNTDs needs to be extended in challenging activities of earthquake prediction and oil exploration.

\section{CONTINUING PROJECTS, PLANS AND FUTURE DIRECTIONS}

The present $\mathrm{R} \& \mathrm{D}$ activities in field of nuclear tracks and their applications in Pakistan are gaining strength due to multidisciplinary training of young members of the nuclear track community in developed countries. The active continued projects at PINSTECH and PIEAS include preparation of radon map of Pakistan, examination of fragmentation processes of relativistic projectiles on different targets, cosmic rays and search for light magnetic monopoles, fabrication and further research on nanomaterials, earthquake prediction, measurements of radionuclides in drinking water and other foods, and radiation damage. Intelligent designs for the studies of antiproton induced reactions using SSNTDs are also in process.

New directions in any research field are an important question [94,95] around the world. A bird eye view of SSNTDs research shows that more success was achieved by those who had worked on different inter-linked research areas [96-101]. Multiplication of existing ideas is one way of generating novel refined ideas and extension in applications of the field [102]. The question of nuclear track formation is still not completely resolved and has a number of ambiguities. The complete picture of nuclear track formation might come up by investigating nuclear track formation near detection thresholds in track recording materials along with ion implantation in semiconductors using latest techniques like atomic force mi- croscopy, secondary electron microscopy and deep level transient spectroscopy. In semiconductors, intensity of radiation damage is very low due to limited dose and provides the chance of studying the fundamental building blocks of latent tracks. It is a proven fact that irradiation induced point defects in semiconductors trap charge carriers, electrons and holes [103,104]. A similar role of electron trapping by defects, generated just after penetration of a particle in a solid, is expected in all materials including solid state nuclear track detectors [105].

Containment and final disposal of high-level nuclear waste is an old problem, but still without a reasonably safe solution. Now, it needs urgent attention due to increasing volume of nuclear waste worldwide. The permanent disposal of high-level nuclear wastes [106-109] is gaining a new momentum [108] due to the need for more electricity with minimal emission of $\mathrm{CO}_{2}$. Spectrum of radiations from nuclear wastes containers penetrates into the containment in a way similar to track forming particles. Understanding the impact of a single radiation (a particle or a photon) on containment material is very important to determine to integrated effect of radiation. Ion channelling $[110,111]$ is another technique having some similarity with nuclear track detection. Recently, the present author used his experience with the nuclear track detection technique [112] and RBS/channelling $[113,114]$ to propose a new method for monitoring the radiation damage in nuclear waste containers [11]. Nuclear track detection technique can be co-used with ion channeling and other experimental techniques, for instance X-ray Photoelectron Spectroscopy (XPS), to increase the accuracy and precision of the measurement of the radiation damage in nuclear waste containers. Due to additional facilities becoming available at PINSTECH, PIEAS and other universities in Pakistan, it seems that a good fraction of nuclear track scientist will proceed their research in the field of nanotechnology in coming years. As Pakistan have a trained academics and scientists in the field of nuclear track detection technology but lacked exposure facilities, latest measurement technologies. So, it can keep this research up through international collaborations which are getting more popular now [115117]. Figure 18 shows images related to nuclear track research in Pakistan, especially PINSTECH) and supportive infrastructure, superimposed on an elaborating painting, detail of which is given in the caption.

\section{CONCLUSION}

A brief and thematically structured state of the art review of nuclear track research activities in Pakistan is presented here with clear and systematic discussions with perspectives of applications and future directions. Physical pictures of processes of latent track formation, their 


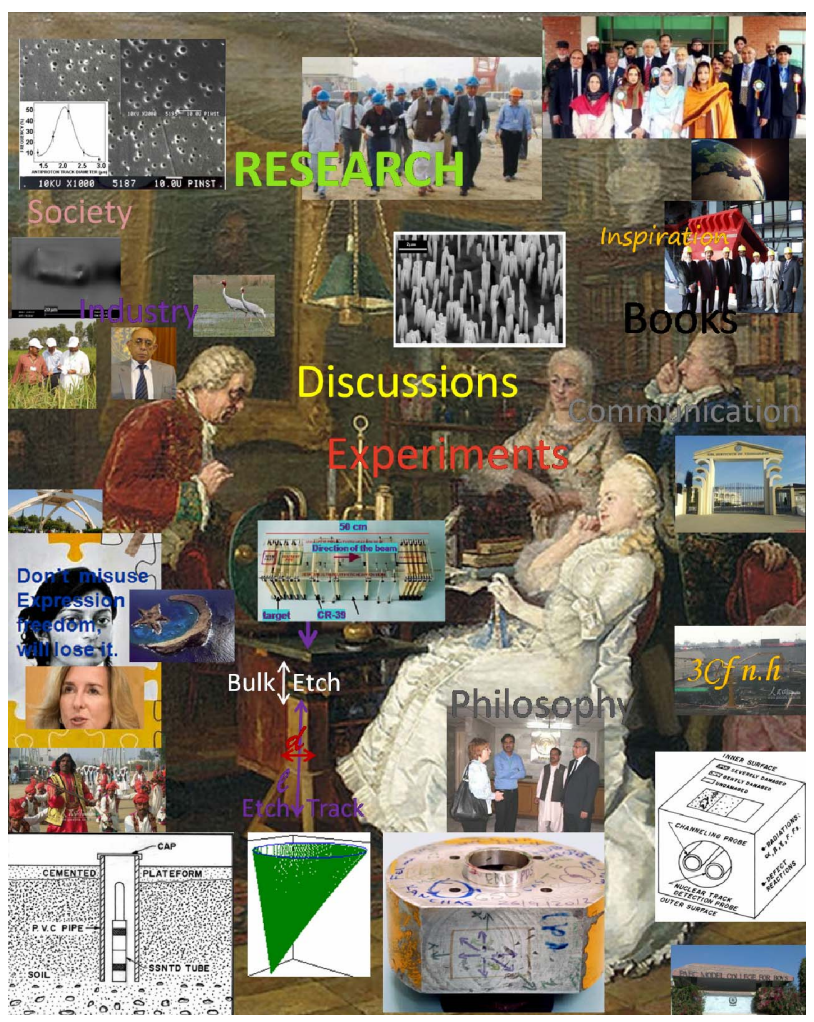

Figure 18. The background of the figure is the 1884 painting by Ivan Fyodorov depicting the 1764 meeting of Empress Catherine the Great with renowned Russian polymath Mikhail Lomonosov, at left. Superimposed are images related to nuclear track research in Pakistan, especially PINSTECH) and supportive infrastructure.

annealing and chemical etching are presented in an inclusive manner. Essential mathematical details are also added. Nuclear tracks based results from different fields of nuclear physics, chemical physics, geophysics and environment are described in coherent style. This investigation is useful for further development of nuclear track detection technology in Pakistan and in countries with similar infrastructure around the globe.

\section{ACKNOWLEDGMENTS}

The author is thankful Dr. H. A. Khan, Dr. I. E. Qureshi, Dr. A.A Qureshi, Dr. K. Jamil, Dr. S. Manzoor, Dr. M. I. Shahzad, Dr. Gul Sher, Dr. N. U. Khattak, Fazal-ur-Rahman, S. Ali, Eng. Mr. M. Akram, Dr. Tanvir Ahmed, Kanwal Naaz, Ms. Fariha Malik, Dr. J. I. Akhter, Eng. Nisar Ahmad, Eng. Iqbal Hussain, Dr. Javed Bashir, Mr. M. Akhter, Dr. Muhammad Iqbal, Parveen Akhter, Dr. Adnan Suhail, Nori, Eng. N. K. Qazi, Dr. Shafqat Karim, Dr. Maaz Khan, Dr. Matiullah, Mr. M. Akhtar, Mr. S. Usman, Dr. B. Suleman, Mr. Tariq Suleija, Dr. J. I. Akhter, Naseem Abbasi, Babar Abbasi, Dr. Ayesha (NIBGE, Faislabad), Dr. Maria Sultan, Dr. Nancy Kalish, Dr. N. Adil, Dr. Dietrich Hermsdorf, Dresden, Germany, Dr. Scandolo, Dr. Shahid Qamar, AS-ICTP, Italy, Dr. Walter Scandale, CERN, Switzerland, Prof. A. R. Peaker, Dr. Vladimir Markevich, Dr. Ian Hawkins, University of Manchester, Dr. Hallen, NUH, Singapore, for discussions. Thanks for the Financial help from Higher Education Commission of Pakistan (HEC) and the project Pakistan's Nuclear and Fusion Development Program (NAFDEP), Collaborative research project of institutes/organizations/companies SPD, PAEC,
KRL, NESCOM, SUPARCO, PCSIR, NCP, NADRA, D \& FA, PINTEL, CNPs, KNPs, PAKMAK, LAZERNIE, PFAUJ, PAIR, PNAVY, PRANGE, PINTEL, NSAFEF, EUETRUST, Kashmamadhelp, GEOISOTOPE, OKMEANSUK, PIMEDS, MISI, TRANSPO, BALTHOKRAY, IPOL, MANMAUJ, MAKMEDINA.

\section{REFERENCES}

[1] Westphal, A.J., Price, P.B., Weaver, B.A. and Afanasiev, V.G. (1998) Evidence against stellar chromospheric origin of Galactic cosmic rays. Nature, 396, 50-52. $\underline{\text { doi: } 10.1038 / 23887}$

[2] Fleischer, R.L., Price, P.B., Symes, E.M. and Miller, D.S. (1964) Fission-track ages and track-annealing behavior of some Micas. Science, 143, 349-351. doi:10.1126/science.143.3604.349

[3] Dartyge, E., Daraud, J.P., Langevin, Y. and Maurette, Y. (1981) New model of nuclear particle tracks in dielectric minerals. Physical Review B, 23, 5213-5229. doi:10.1103/PhysRevB.23.5213

[4] Tombrello, T.A., Wif, C.A., Itoh, N. and Nakayama, T. (1984) Formation of ion damage tracks. Physics Letters A, 100, 42-44. doi:10.1016/0375-9601(84)90351-7

[5] Price, P.B., Gerbier, G., Park, H.S. and Salamon, M.H. (1987) Systematics of annealing of tracks of relativistic nuclei in phosphate glass detectors. Nuclear Instruments and Methods B, 28, 53-55. doi:10.1016/0168-583X(87)90035-8

[6] Rana, M.A. and Qureshi, I.E. (2002) Studies of CR-39 etch rates. Nuclear Instruments and Methods B, 198, 129134. doi:10.1016/S0168-583X(02)01526-4

[7] Somogi, G. (1980) Development of etched nuclear tracks. Nuclear Instruments and Methods, 173, 21-42. doi:10.1016/0029-554X(80)90565-0

[8] Pandey, A.K., Kalsi, P.C. and Iyer, R.H. (1998) Effects of high intensity ultrasound in chemical etching of particle tracks in solid state nuclear track detectors. Nuclear Instruments and Methods B, 134, 393-399. doi:10.1016/S0168-583X(97)00735-0

[9] Fink, D., Ghosh, S., Klett, R., Dwivedi, K.K., Kobayashi, Y., Hirata, K., Vacik, J., Hnatowicz, V., Cervena, J. and Chadderton, L.T. (1998) Transport processes during the incubation time of ion track etching in polymers. Nuclear Instruments and Methods B, 146, 486-490. doi:10.1016/S0168-583X(98)00461-3

[10] Farnan, I., Cho, H. and Weber, W.J. (2007) Quantification of actinide $\alpha$-radiation damage in minerals and ceramics. Nature, 445, 190-193. doi:10.1038/nature05425

[11] Rana, M.A. (2008) A new method for monitoring the radiation damage in nuclear waste containers using ion channelling. Annals of Nuclear Energy, 35, 1580-1583. doi:10.1016/j.anucene.2008.01.015

[12] Rose, P.H. and Ryding, G. (2006) Concepts and designs of ion implantation equipment for semiconductor processing. Review of Scientific Instruments, 77, 111101. doi:10.1063/1.2354571

[13] Ditlov, V.A., Awad, E.M., Hermsdorf, D. and Fromm, M. (2008) Interpretation of the bulk etching process in LR- 
115 detectors by the many-hit model. Radiation Measurements, 43, S82-S86. doi:10.1016/i.radmeas.2008.03.071

[14] Tahiri, T.A., Matiullah and Subhani, M.S. (2003) Molten $\mathrm{Ba}(\mathrm{OH})_{2} \cdot 8 \mathrm{H}_{2} \mathrm{O}$ as an etchant for CR-39 detector. $R a-$ diation Measurements, 37, 205-210. doi:10.1016/S1350-4487(03)00030-1

[15] Matiullah, Dogar, A.H., Ahmad, N., Amin, M. and Kudo, K. (1999) Gamma dosimetry with CR-39 etch track detector. Japanese Journal of Applied Physics (Part 1), 38, 3761-3762. doi:10.1143/JJAP.38.3761

[16] Husaini, S.N., Khan, E.U., Khattak, N.U., Qureshi, A.A., Malik, F., Qureshi, I.E., Karim, T. and Khan, H.A. (2002) The study of crystalline etch products of CR-39. Radiation Measurements, 35, 3-5. doi:10.1016/S1350-4487(01)00259-1

[17] Khan, E.U., Husaini, S.N., Malik, F., Sajid, M., Karim, S. and Qureshi, I.E. (2002) A quick method for maintaining the molarity of $\mathrm{NaOH}$ solution during continuous etching of CR-39. Radiation Measurements, 35, 41-45. doi:10.1016/S1350-4487(01)00260-8

[18] Malik, F., Khan, E.U., Qureshi, I.E., Husaini, S.N., Sajid, M., Karim, S. and Jamil, K. (2002) Swelling in CR-39 and its effect on bulk etch-rate. Radiation Measurements, 35, 301-305. doi:10.1016/S1350-4487(02)00053-7

[19] Khan, H.A., Lund, T., Vater, P., Brandt, R. and Tuyn, J.W.N. (1983) Some gross features of the interaction of semirelativistic ${ }^{16} \mathrm{O}$ and ${ }^{12} \mathrm{C}$ ions with ${ }^{197} \mathrm{Au}$ targets. Physical Review $C, \mathbf{2 8}, 1630-1634$. doi:10.1103/PhysRevC.28.1630

[20] Dörschel, B., Fülle, D., Hartmann, H., Hermsdorf, D., Kadner, K. and Radlach, Ch. (1997) Measurement of track parameters and etch rates in proton-irradiated CR- 39 detectors and simulation of neutron dosimeter. Radiation Protection Dosimetry, 69, 267-274. doi:10.1093/oxfordjournals.rpd.a031913

[21] Rana, M.A. (2012) Mechanisms and kinetics of nuclear track etching and annealing: Free energy analysis of damage in fission fragment tracks. Nuclear Instruments and Methods A, 672, 57-63. doi:10.1016/j.nima.2011.12.121

[22] Rana, M.A., Qureshi, I.E., Manzoor, S., Khan, E.U., Shahzad, M.I. and Sher, G. (2001) Activation energy for the annealing of nuclear tracks in SSNTDs. Nuclear Instruments and Methods B, 179, 249-254. doi:10.1016/S0168-583X(01)00574-2

[23] Rana, M.A., Qureshi, I.E., Manzoor, S., Khan, E.U., Shahzad, M.I. and Khan, H.A. (2000) Thermal annealing of fission fragment radiation damage in CR-39. Nuclear Instruments and Methods $B, \mathbf{1 7 0}, 149-155$. doi:10.1016/S0168-583X(00)00154-3

[24] Rana, M.A. (2007) A model for annealing of nuclear tracks in solids. Radiation Measurements, 42, 317-322. doi:10.1016/j.radmeas.2007.01.039

[25] Khan, E.U., Qureshi, I.E., Shahzad, M.I., Khattak, F.N. and Khan, H.A. (2001) Emission of intermediate mass fragments in the heavy ion interaction of $(14.0 \mathrm{MeV} / \mathrm{u})$ $\mathrm{Pb}+\mathrm{Au}$. Nuclear Physics A, 690, 723-730. doi:10.1016/S0375-9474(00)00697-7
[26] Shahzad, M.I., Qureshi, I.E., Manzoor, S. and Khan, H.A. (1999) Sequential fission process observed in the reaction $(16.7 \mathrm{MeV} / \mathrm{u}){ }^{238} \mathrm{U}+{ }^{\text {nat. }} \mathrm{Au}$ using mica as dielectric track detector. Nuclear Physics A, 645, 92-106. doi:10.1016/S0375-9474(98)00554-5

[27] Khan, H.A., Qureshi, I.E., Jamil, K., Brandt, R. and Kraft, G. (1988) Nuclear reactions of relativistic ${ }^{238} \mathrm{U}$ - and ${ }^{139}$ La-ions with light target atoms. Nuclear Tracks and Radiation Measurements, 15, 403-409. doi:10.1016/1359-0189(88)90172-0

[28] Qureshi, I.E., Khan, H.A., Rashid, K., Gottschalk, P.A., Vater, P. and Brandt, R. (1988) Four-fragment exit channel in the interaction of $1050 \mathrm{MeV}{ }^{84} \mathrm{Kr}$ with $\mathrm{U}$ studied with mica detectors. Physical Review C, 37, 393-396. doi:10.1103/PhysRevC.37.393

[29] Saffarini, G., Dwaikat, N., El-Hasan, M., Sato, F., Kato, Y. and Iida, T. (2012) The effect of infrared laser on the activation energy of CR-39 polymeric detector. Nuclear Instruments and Methods A, 680, 82-85. doi:10.1016/j.nima.2012.04.003

[30] Rana, M.A. and Manzoor, S. (2008) Examining the fragmentation of $158 \mathrm{~A} \mathrm{GeV}$ lead ions on copper target: Charge-changing cross sections. Radiation Measurements, 43, 1383-1389. doi:10.1016/j.radmeas.2008.05.004

[31] Cecchini, S., et al. (2008) Fragmentation cross sections of $\mathrm{Fe}^{26+}, \mathrm{Si}^{14+}$ and $\mathrm{C}^{6+}$ ions of $0.3-10 A \mathrm{GeV}$ on polyethylene, CR39 and aluminum targets. Nuclear Physics A, 807, 206-213. doi:10.1016/j.nuclphysa.2008.03.017

[32] Rana, M.A. and Manzoor, S. (2008) Total fragmentation cross section of 158-A-GeV lead projectiles in $\mathrm{Cu}$ target. Chinese Physics Letters, 25, 3208-3211. doi:10.1088/0256-307X/25/9/031

[33] Sher, G., Shahzad, M.I. and Hussain, M. (2008) Fragmentation of $158 \mathrm{~A} \mathrm{GeV} \mathrm{Pb}$ ions with $\mathrm{Bi}$ target. Radiation Measurements, 42, 1692-1695. doi:10.1016/j.radmeas.2007.09.006

[34] Manzoor, S., et al. (2007) Nuclear track detectors for environmental studies and radiation monitoring. Nuclear Physics B-Proceedings Supplement, 172, 92-96. doi:10.1016/j.nuclphysbps.2007.07.017

[35] Balestra, S., et al. (2007) Bulk etch rate measurements and calibrations of plastic nuclear track detectors. $\mathrm{Nu}$ clear Instruments and Methods B, 254, 254-258. doi:10.1016/i.nimb.2006.11.056

[36] Qureshi, I.E., et al. (2005) Study of projectile fragmentation in the reaction $(158 \mathrm{~A} \mathrm{GeV}) \mathrm{Pb}+\mathrm{Pb}$ using CR-39. Radiation Measurements, 40, 437-441. doi:10.1016/j.radmeas.2004.11.013

[37] Manzoor, S., et al. (2001) Charge identification in CR-39 nuclear track detector using relativistic lead ion fragmentation. Nuclear Instruments and Methods A, 453, 525-529. doi:10.1016/S0168-9002(00)00470-8

[38] Sanchez, I.C., Colson, J.P. and Eby, R.K. (1973) Theory and observations of polymer crystal thickening. Journal of Applied Physics, 44, 4332-4339. doi:10.1063/1.1661961

[39] Scheidenberger, C., et al. (2004) Charge-changing interactions of ultrarelativistic $\mathrm{Pb}$ nuclei. Physical Review $C, \mathbf{7 0}$, 
014902. doi:10.1103/PhysRevC.70.014902

[40] Kunert, T. and Schmidt, R. (2001) Excitation and fragmentation mechanisms in ion-fullerene collisions. Physical Review Letters, 86, 5258-5261.

doi:10.1103/PhysRevLett.86.5258

[41] Jurado, B., Sshmitt, C., Schmidt, K.-H., Benlliure, J., Enqvist, T., Junghans, A.R., Kelic, A. and Rejmund, F. (2004) Transient Effects in fission from new experimental signatures. Physical Review Letters, 93, 072501. doi:10.1103/PhysRevLett.93.072501

[42] Ricciardi, M.V., Ignatyuk, A.V., Kelić, A., Napolitani, P., Rejmund, F., Schmidt, K.-H. and Yordanov, O. (2004) Complex nuclear-structure phenomena revealed from the nuclide production in fragmentation reactions. Nuclear Physics A, 733, 299-318. doi:10.1016/j.nuclphysa.2004.01.069

[43] Rana, M.A., Khan, E.U., Qureshi, I.E., Shahzad, M.I., Sher, G., Manzoor, S. and Qureshi, I.E. (2007) Characteristics of antiproton tracks in CR-39. Radiation Measurements, 42, 125-129. doi:10.1016/j.radmeas.2006.12.002

[44] Rana, M.A., Khan, E.U., Qureshi, I.E., Malik, F., Shahzad, M.I., Sher, G., Manzoor, S. and Khan, H.A. (2006) Annihilation of antiprotons in light nuclei. Chinese Physics Letters, 23, 1716-1719. doi:10.1088/0256-307X/23/7/017

[45] Khan, H.A., Khan, N.A. and Peterson, R.J. (1987) Fission induced in ${ }^{\text {nat }} \mathrm{U},{ }^{\text {nat }} \mathrm{Pb},{ }^{197} \mathrm{Au}$, and ${ }^{165} \mathrm{Ho}$ by 80 and 100 $\mathrm{MeV} \pi^{+}$and $\pi^{-}$. Physical Review $C, 35,645-650$. doi:10.1103/PhysRevC.35.645

[46] Khan, H.A., Qureshi, I.E., Shahzad, M.I., Manzoor, S., Farooq, M.A., Sher, G., Khan, E.U. and Peterson, R.J. (1999) Preliminary results of fission induced by (1068 $\mathrm{MeV}) \pi^{-}$in $\mathrm{Cu}, \mathrm{Sn}, \mathrm{Au}$ and $\mathrm{Bi}$ using CR-39 detectors. Radiation Measurements, 31, 559-562. doi:10.1016/S1350-4487(99)00198-5

[47] Khan, H.A., Qureshi, I.E., Shahzad, M.I., Manzoor, S., De Barros, S. and Peterson, R.J. (1997) Pion-induced fission in tin and bismuth observed with makrofol detectors. Radiation Measurements, 28, 287-290. doi:10.1016/S1350-4487(97)00084-X

[48] Peterson, R.J., de Barros, S., de Souza, I., Gaspar, M.B., Khan, H.A. and Manzoor, S. (1995) Mass and energy dependence of pion induced fission. Zeitschrift für Physik A, 352, 181-189.

[49] Yasin, A.B., Shahzad, M.I., Qureshi, I.E., Sher, G. and Peterson, R.J. (2006) Experimental studies and cascadeexciton model analysis of negative pion induced fission in gold and bismuth. Nuclear Physics A, 765, 390-400. doi:10.1016/j.nuclphysa.2005.11.005

[50] Khan, H.A., Khan, N.A. and Peterson, R.J. (1990) Pion induced interactions in tantalum, europium, antimony and zirconium. Nuclear Instruments and Methods B, 51, 421424. doi:10.1016/0168-583X(90)90562-9

[51] Khan, H.A., Khan, N.A. and Peterson, R.J. (1991) Mass dependence of positive pion-induced fission. Physical Review C, 43, 250-253. doi:10.1103/PhysRevC.43.250

[52] Greisen, K. (1966) End to the cosmic-ray spectrum? Phy- sical Review Letters, 16, 748-750. doi:10.1103/PhysRevLett.16.748

[53] Zatsepin, G.T. and Kuz'min, V.A. (1966) Upper limit of the spectrum of cosmic rays. Journal of Experimental and Theoretical Physics Letters, 4, 78-80.

[54] Mashnik, S.G. (1995) User's manual for the code CEM95. http://www.nea.fr/abs/html/iaea1247.html

[55] Gudima, K.K., Mashnik, S.G. and Toneev, V.D. (1983) Cascade-exciton model of nuclear reactions. Nuclear Physics A, 401, 329-361. doi:10.1016/0375-9474(83)90532-8

[56] Hicks, K.H., et al. (1985) Fission of heavy nuclei induced by energetic pions. Physical Review C, 31, 1323-1333. doi:10.1103/PhysRevC.31.1323

[57] Khan, H.A. and Qureshi, A.A. (1994) Solid-state nuclear track detection-A useful geological geophysical tool. $\mathrm{Nu}$ clear Geophysics, 8, 1-37.

[58] Rana, M.A. (2008) Certain aspects of high level radioactive wastes-A brief note on the problem. The Nucleus, 45, 91-99. www.thenucleuspak.org.pk

[59] Fleischer, R.L., Price, P.B. and Walker, R.M. (1975) Nuclear tracks in solids. University of California Press, Berkeley.

[60] Khan, H.A. and Durrani, S.A. (1972) Prolonged etching factor in SSTD and its applications. Radiation Effects, 13, 257-266. doi:10.1080/00337577208231188

[61] Durrani, S.A. and Khan, H.A. (1971) Obsidian source identification by fission track analysis. Nature, 233, 242-245. doi: $10.1038 / 233242 \mathrm{a} 0$

[62] King, C.Y. (1978) Radon emanation on San Andreas fault. Nature, 271, 516-519. doi:10.1038/271516a0

[63] Durrani, S.A. and Khan, H.A. (1970) Annealing of fission tracks in tektites: Corrected ages of bediasites. Earth and Planetary Science Letters, 9, 431-445. doi:10.1016/0012-821X(70)90010-5

[64] Khattak, N.U., Qureshi, A.A., Akram, M., Khan, M.A., Qureshi, I.E., Mehmood, K. and Khan, H.A. (2001) Unroofing history of the Sillai Patti granite gneiss, Pakistan: Constraints from zircon fission-track dating. Radiation Measurements, 34, 409-413. doi:10.1016/S1350-4487(01)00196-2

[65] Qureshi, A.A., Khattak, N.U., Sardar, M., Tufail, M., Akram, M., Iqbal, T. and Khan, H.A. (2001) Determination of uranium contents in rock samples from Kakul phosphate deposit, Abbotabad (Pakistan), using fission-track technique. Radiation Measurements, 34, 355-359. doi:10.1016/S1350-4487(01)00185-8

[66] Qureshi, A.A., Karim, T., Rizvi, S.H.N., Tahir, M., Rabbani, M., Mehmood, K. and Khan, H.A. (1995) Fission track dating of biotite mica from Antarctica. Radiation Measurements, 25, 521-522. doi:10.1016/1350-4487(95)00144-4

[67] Qureshi, A.A., Mehmood, K., Karim, T., Jamil, K. and Khan, H.A. (1995) Use of mica in fission track dating. Radiation Measurements, 25, 519-520. doi:10.1016/1350-4487(95)00143-3

[68] Khattak, N.U., Qureshi, A.A., Hussain, S.S., Akram, M., Mateen, A. and Khan, H.A. (2001). Study of the tectonic 
uplift history of the Sillai Patti granitic gneiss, Pakistan: Constraints from zircon fission-track dating. Journal of Asian Earth Sciences, 20, 1-8. doi:10.1016/S1367-9120(01)00018-9

[69] Khattak, N.U., Qureshi, A.A., Akram, M., Ullah, K., Azhar, M. and Khan, M.A. (2005) Unroofing history of the Jambil and Jawar carbonatite complexes from NW Pakistan: Constraints from fission-track dating of apatite. Journal of Asian Earth Sciences, 25, 643-652. doi:10.1016/j.jseaes.2004.07.005

[70] Durrani, S.A. (2008) Nuclear tracks today: Strengths, weaknesses, challenges. Radiation Measurements, 43, S26-S33. doi:10.1016/j.radmeas.2008.03.044

[71] Tahir, S.N.A., Jamil, K., Zaidi, J.H., Arif, M. and Ahmed, N. (2006) Activity Concentration of ${ }^{137} \mathrm{Cs}$ in soil samples from Punjab province (Pakistan) and estimation of gammaray dose rate for external exposure. Radiation Protection Dosimetry, 118, 345-351. doi:10.1093/rpd/nci351

[72] Jamil, K. and Ali, S. (2001) Estimation of radon concentrations in coal mines using a hybrid technique calibration curve. Journal of Environmental Radioactivity, 54, 415422. doi:10.1016/S0265-931X(00)00175-2

[73] Jamil, K., Ali, S., Iqbal, M., Qureshi, A.A. and Khan, H.A. (1998) Measurements of radionuclides in coal samples from two provinces of Pakistan and computation of External $\gamma$ ray dose rate in coal mines. Journal of Environmental Radioactivity, 41, 207-216. doi:10.1016/S0265-931X(97)00094-5

[74] Jamil, K., Al-Ahmady, K.K., Fazal-ar-Rehman, Safdar A., Qureshi, A.A. and Khan, H.A. (1997) Relative performance cf different types of passive dosimeters employing solid stale nuclear track detectors. Health Physics, 73, 629632. doi:10.1097/00004032-199710000-00006

[75] Jamil, K., Rehman, F.-U., Ali, S. and Khan, H.A. (1997) Determination of equilibrium factor between radon and its progeny using surface barrier detector for various shapes of passive radon dosimeters. Nuclear Instruments and Methods $A, \mathbf{3 8 8}, 267-272$. doi:10.1016/S0168-9002(97)00307-0

[76] Jamil, K., Ali, S., Qureshi, I.E., Rehman, F., Khan, H.A., Manzoor, S., Waheed, A. and Cherubini, R. (1997) Experimental and simulation study of neutron dosimetry at various neutron energies. Radiation Measurements, 28, 495498. doi:10.1016/S1350-4487(97)00127-3

[77] Kudo, K., Khan, S. and Khan, H.A. (1991) Fast neutron spectrometry with electrochemically etched CR-39 detectors. Nuclear Tracks and Radiation Measurements, 19, 505-506. doi:10.1016/1359-0189(91)90256-H

[78] Waheed, A., Manzoor, S., Cherubini, R., Moschini, G., Lembo, L. and Khan, H.A. (1990) A more suitable etching condition to register low energy proton tracks in CR39 for neutron dosimetry. Nuclear Instruments and Methods $B, \mathbf{4 7}, 320-328$. doi:10.1016/0168-583X(90)90765-M

[79] Khan, H.A. and Khan, N.A. (1980) Fast neutron dosimetry using a CR-39 plastic track detector. Nuclear Instruments and Methods, 178, 491-497. doi:10.1016/0029-554X(80)90829-0

[80] Malik, F., Khan, E.U., Qureshi, I.E., Husaini, S.N., Ah- mad, W., Rajput, M.U. and Raza, Q. (2006) A new method for the determination of unknown neutron fluence for 14.0 MeV. Physica B, 385-386, 1318-1320. doi:10.1016/j.physb.2006.06.063

[81] Khan, E.U., Malik, F., Qureshi, I.E., Husaini, S.N., Ali, N. and Mehmood, A. (2005) Measurement of neutron fluence with CR-39 using a UV spectrophotometer. Radiation Measurements, 40, 583-586. doi:10.1016/i.radmeas.2005.02.016

[82] Akram, M., Khattak, N.U., Ullah, I. and Tufail, M. (2008) Fission track estimation of uranium concentrations in liquid homeopathic medicine samples. Radiation Measurements, 43, S527-S531.

doi:10.1016/j.radmeas.2008.03.011

[83] Akram, M., Khattak, N.U., Qureshi, A.A., Iqbal, A., Tufail, M. and Qureshi, I.E. (2004) Fission track estimation of uranium concentrations in drinking water. Health Physics, 86, 296-302. doi:10.1097/00004032-200403000-00006

[84] Akram, M., Khattak, N.U., Qureshi, A.A., Iqbal, A., Ullah, K. and Qureshi, I.E. (2004) Neutron induced radiography in the determination of boron in drinking water. Journal of Radionuclear and Nuclear Chemistry, 261, 429-435. doi:10.1023/B:JRNC.0000034881.06566.26

[85] Husaini, S.N., Zaidi, J.H., Malik, F. and Arif, M. (2008) Application of nuclear track membrane for the reduction of pollutants in the industrial effluent. Radiation Measurements, 43, S607-S611. doi:10.1016/j.radmeas.2008.03.070

[86] Fink, D., Saad, A., Dhamodaran, S., Chandra, A., Fahrner, W.R., Hoppe, K. and Chadderton, L.T. (2008) Multiparametric electronic devices based on nuclear tracks. $R a$ diation Measurements, 43, S546-S551. doi:10.1016/j.radmeas.2008.03.034

[87] Apel, P.Y., Blonskaya, I.V., Dmitriev, S.N., Mamonova, T.I., Orelovitch, O.L., Sartowska, B. and Yamauchi, Y. (2008) Surfactant-controlled etching of ion track nanopores and its practical applications in membrane technology. Radiation Measurements, 43, S552-S559. doi:10.1016/j.radmeas.2008.04.057

[88] Spohr, R. (2008) Real-time control of track etching and recent experiments relevant to micro and nano fabrication. Radiation Measurements, 43, S560-S570. doi:10.1016/j.radmeas.2008.03.078

[89] Karim, S., Maaz, K., Ali, G. and Ensinger, W. (2009) Diameter dependent failure current density of gold nanowires. Journal of Physics D: Applied Physics, 42, 185403. doi:10.1088/0022-3727/42/18/185403

[90] Maaz, K., Karim, S., Mashiatullah, A., Liu, J., Hou, M.D., Sun, Y.M., Duan, J.L., Yao, H.J., Mo, D. and Chen, Y.F. (2009) Structural analysis of nickel doped cobalt ferrite nanoparticles prepared by coprecipitation route. Physica $B$, 404, 3947-3951. doi:10.1016/j.physb.2009.07.134

[91] Karim, S., Ensinger, W., Cornelius, T.W., Khan, E.U. and Neumann, R. (2008) Tuning the characteristics of electrochemically fabricated gold nanowires. Journal of Nanoscience and Nanotechnology, 8, 5659-5666. doi:10.1166/jnn.2008.258 
[92] Karim, S., Ensinger, W., Cornelius, T.W. and Neumann, R. (2008) Investigation of size effects in the electrical resistivity of single electrochemically fabricated gold nanowires. Physica E, 40, 3173-3178. doi:10.1016/j.physe.2008.05.011

[93] Karim, S., Toimil-Molares, M.E., Balogh, A.G., Ensinger, W., Cornelius, T.W., Khan, E.U. and Neumann, R. (2006) Morphological evolution of Au nanowires controlled by Rayleigh instability. Nanotechnology, 17, 5954-5959. doi:10.1088/0957-4484/17/24/009

[94] Price, P.B. (2008) Recent applications of nuclear tracks in solids. Radiation Measurements, 43, S13-S25. doi:10.1016/j.radmeas.2008.04.002

[95] Lang, D.V. (2007) Recalling the origins of DLTS. Physica $B, \mathbf{4 0 1}-\mathbf{4 0 2}, 7-9$. doi:10.1016/j.physb.2007.08.102

[96] Fleischer, R.L. (2005) The distribution of boron in AlRu: Effect on ductility and toughness. Acta Materialia, 9, 2623-2627. doi:10.1016/j.actamat.2005.02.021

[97] Price, P.B. (2008) Overview of the conference. Radiation Measurements, 43, S662-S664. doi:10.1016/j.radmeas.2008.03.045

[98] Spohr, R. (2005) Status of ion track technology-Prospects of single tracks. Radiation Measurements, 40, 191202. doi:10.1016/j.radmeas.2005.03.008

[99] Hermsdorf, D., Hunger, M., Starke, S. and Weickert, F. (2007) Measurement of bulk etch rates for poly-allyl-diglycol carbonate (PADC) and cellulose nitrate in a broad range of concentration and temperature of $\mathrm{NaOH}$ etching solution. Radiation Measurements, 42, 1-7. doi:10.1016/j.radmeas.2006.06.009

[100] Dörschel, B., Fülle, D., Hartmann, H., Hermsdorf, D., Kadner, K. and Radlach, Ch. (1997) Dependence of the etch rate ratio on the energy loss in proton irradiated CR-39 detectors and recalculation of etch pit parameters. Radiation Protection Dosimetry, 71, 99-106. doi:10.1093/oxfordjournals.rpd.a032046

[101] Smilgys, B., Guedes, S., Hadler, J.C., Coelho, P.R.P., Alencar, I., Soares, C.J. and Salim, L.A. (2011) Manufacturing of boron thin films for the measurement of the ${ }^{10} \mathrm{~B}(\mathrm{n}, \alpha)^{7} \mathrm{Li}$ reaction in BNCT. Proceedings of Science, XXXIV BWNP, Article 35.

[102] Rana, M.A. (2008) How to achieve precision and reliability in experiments using nuclear track detection technique? Nuclear Instruments and Methods A, 592, 354-360. doi:10.1016/j.nima.2008.04.025

[103] Dixit, S.K., Zhou, X.J., Schrimpf, R.D., Fleetwood, D.M., Pantelides, S.T., Choi, R., Bersuker, G. and Feldman, L.C. (2007) Radiation induced charge trapping in HfO-based MOSFETs. IEEE Transactions on Nuclear Science, 54, 18831890. doi:10.1109/TNS.2007.911423

[104] Hjalmarson, H.P., Vogl, P., Wolford, D.J. and Dow, J.D. (1980) Theory of substitutional deep traps in covalent. Physical Review Letters, 44, 810-813. doi:10.1103/PhysRevLett.44.810
[105] Fleischer, R.L. (2004) Fission tracks in solids-Production mechanisms and natural origins. Journal of Material Science, 39, 3901-3911. doi:10.1023/B:JMSC.0000031471.17343.32

[106] Ewing, R.C. (2001) The design and evaluation of nuclearwaste forms: Clues from mineralogy. Canadian Mineralogist, 39, 697-715. doi:10.2113/gscanmin.39.3.697

[107] Ewing, R.C. (2006) The nuclear fuel cycle: A role for mineralogy and geochemistry. Elements, 2, 331-334. doi:10.2113/gselements.2.6.331

[108] Ewing, R.C. (2007) Displaced by radiation. Nature, 445, 161-162. doi:10.1038/445161a

[109] Butler, D. (2004) Nuclear power's new dawn. Nature, 429, 238-240. doi:10.1038/429238a

[110] Gemmell, D.S. (1974) Channeling and related effects in the motion of charged particles through crystals. Review of Modern Physics, 46, 129-227. doi:10.1103/RevModPhys.46.129

[111] Breese, M.B.H., King, P.J.C., Smulders, P.J.M. and Grime, G.W. (1995) Dechanneling of $\mathrm{MeV}$ protons by $60^{\circ}$ dislocations. Physical Review B, 51, 2742-2750. doi:10.1103/PhysRevB.51.2742

[112] Rana, M.A. (2008) On the long standing question of nuclear track etch induction time: Surface-cap model. $\mathrm{Nu}$ clear Instruments and Methods B, 266, 271-276. doi:10.1016/j.nimb.2007.10.036

[113] Chua, S. J. (2003) A study of the material loss and other processes involved during annealing of $\mathrm{GaN}$ at growth temperatures. Chemical Physics Letters, 380, 105-110. doi:10.1016/j.cplett.2003.09.019

[114] Rana, M.A., Osipowicz, T., Choi, H.W., Breese, M.B.H., Watt, F. and Chua, S.J. (2003) Stoichiometric and structural alterations in $\mathrm{GaN}$ thin films during annealling. $\mathrm{Ap}$ plied Physics A, 77, 103-108. doi:10.1007/s00339-003-2102-Z

[115] Ccecchini, S., Giacomelli, G., Giorgini, M., Mandrioli, G., Patrizii, L., Popa, V., Serra, P., Sirri, G. and Spurio, M. (2002) Fragmentation cross sections of $158 \mathrm{~A} \mathrm{GeV} \mathrm{Pb}$ ions in various targets measured with CR39 nuclear track detectors. Nuclear Physics A, 707, 513-524. doi:10.1016/S0375-9474(02)00962-4

[116] Zhou, D., Semones, E., O'Sullivan, D., Zapp, N., Weyland, M., Reitz, G., Berger, T. and Benton, E.R. (2010) Radiation measured for MATROSHKA-1 experiment with passive dosimeters. Acta Astronautica, 66, 301-308. doi:10.1016/j.actaastro.2009.06.014

[117] Batusov, Yu.A., Bradnova, V., Hashemi-Nezhad, S.R., Tereshchenko, V.V., Tereshchenko, S.V. (2009) Investigation of fast neutron spectra in the uranium assembly of the experimental setup "energy plus transmutation" in the JINR Nuclotron proton beam at an energy of $1.5 \mathrm{GeV}$. Radiation Measurements, 44, 917-921. doi:10.1016/j.radmeas.2009.10.006 